CENTRE POUR LA RECHERCHE ECONOMIQUE ET SES APPLICATIONS

Document de travail (Docweb) $\mathrm{n}^{0} 1503$

\title{
The Limits of Career Concerns in Federalism: Evidence from China
}

\author{
Petra Persson \\ Ekaterina Zhuravskaya
}

Février 2015 


\title{
The Limits of Career Concerns in Federalism: Evidence from China
}

\begin{abstract}
Performance-based promotion schemes in administrative hierarchies have limitations. Chinese provincial leaders, despite facing strong career concerns, make different policy decisions depending on their career backgrounds. Provincial party secretaries who rose from low to high positions within the province they govern ("locals") spend a higher share of budgetary resources on education and health care and invest less in construction infrastructure than party secretaries who made their most significant career advancements in other provinces ("outsiders"). Identification comes from variation in central leadership and term limits. As the promotion mechanism rewards infrastructure investments, locals are less likely to be promoted at the end of the term. We explore various mechanisms and provide evidence that the difference between locals and outsiders is not driven by knowledge or experience. Several pieces of evidence suggest that locals cater to low-level provincial elites, who helped them rise to power. Thus, local career trajectories limit the power of career concerns by fostering competing allegiances.
\end{abstract}

Keywords: autocracy, career concerns, China, federalism, hierarchies, public goods

JEL Classification: H11, H70, P26

\section{Les limites de considération de carrière dans le système fédéral: Le cas de la Chine}

Résumé: Les schémas de promotion dans les hiérarchies administratives fondés sur la performance ont des limites. Les dirigeants locaux chinois, malgré des préoccupations de carrière fortes, prennent des décisions politiques différentes en fonction de leurs carrières précédentes. Les secrétaires provinciaux du Parti qui ont progressé dans leurs carrières au sein de la province qu'ils gouvernent dépensent une plus grande part des ressources budgétaires sur l'éducation et les soins de santé et investissent moins dans l'infrastructure que les secrétaires du parti qui ont progressé de manière significative dans d'autres provinces. L'identification vient de la variation de dirigeants au niveau central et de la durée limitée de leur mandat. Etant donné que le mécanisme de promotion récompense les investissements d'infrastructure, les secrétaires du Parti qui avancent dans leurs carrières dans leur province sont moins susceptibles d'être promus à la fin du mandat. Nous explorons divers mécanismes et montrons que la différence entre les dirigeants locaux et ceux venant de l'extérieur n'est pas influencée par les compétences ou l'expérience. Plusieurs éléments de preuve suggèrent que les dirigeants locaux répondent aux besoins des élites provinciales qui les ont aidés à accéder au pouvoir. 


\title{
The Limits of Career Concerns in Federalism: Evidence from China*
}

\author{
Petra Persson $^{\dagger} \quad$ Ekaterina Zhuravskaya ${ }^{\ddagger}$
}

December 2014

\begin{abstract}
Performance-based promotion schemes in administrative hierarchies have limitations. Chinese provincial leaders, despite facing strong career concerns, make different policy decisions depending on their career backgrounds. Provincial party secretaries who rose from low to high positions within the province they govern ("locals") spend a higher share of budgetary resources on education and health care and invest less in construction infrastructure than party secretaries who made their most significant career advancements in other provinces ("outsiders"). Identification comes from variation in central leadership and term limits. As the promotion mechanism rewards infrastructure investments, locals are less likely to be promoted at the end of the term. We explore various mechanisms and provide evidence that the difference between locals and outsiders is not driven by knowledge or experience. Several pieces of evidence suggest that locals cater to low-level provincial elites, who helped them rise to power. Thus, local career trajectories limit the power of career concerns by fostering competing allegiances.
\end{abstract}

JEL classification: H11, H70, P26

Keywords: career concerns, federalism, hierarchies, public goods, autocracy, China

${ }^{*}$ We are grateful to anonymous referees, Hunt Alcott, Chong-En Bai, Andrei Bremzen, Francesco Caselli, Kate Casey, Stefano DellaVigna, Georgy Egorov, Marcel Fafchamps, Claudio Ferraz, Ray Fisman, Ronny Freier, John Friedman, Sergei Guriev, Irena Grosfeld, Eliana La Ferrara, Samuel Lee, David Daokui Li, Ben Olken, Scott Rozelle, Stephane Straub, Miguel Urquiola, Shang-Jin Wei, and participants of the NBER Summer Institute, the Econometric Society World Congress in Shanghai, the 13th Annual Conference of the International Society for New Institutional Economics at the University of California at Berkeley, the 3rd Global Institute China-Russia Conference at Tsinghua University, the CEPR Political Economy of Development workshop, several anonymous referees, and the participants of numerous seminars for helpful comments. We also thank Ryan Monarch and Lynn Liu for excellent research assistance. Persson gratefully acknowledges funding from Grant \#5001537 from the Social Security Administration and the Hewlett Foundation/IIE Dissertation Fellowship in Population, Reproductive Health and Economic Development.

${ }^{\dagger}$ SIEPR and Department of Economics, Stanford University. Email: perssonp@stanford.edu.

${ }^{\ddagger}$ Paris School of Economics. Email: ezhuravskaya@gmail.com. 


\section{Introduction}

Chinese federalism is characterized by economic decentralization coupled with strong political centralization. Through control over promotion decisions, the central government provides the top provincial officials, the party secretaries, with incentives to adhere to centrally proclaimed goals. The party secretaries, who are appointed for five-year terms, face well-defined promotion criteria that are closely linked to provincial economic performance over the term (Chen et al., 2005; Li and Zhou, 2005). The powerful career concerns faced by high-level officials are considered one of the key drivers of China's economic growth over the last 30 years, and have led many to consider China a model of how a central government can provide officials with efficient career incentives (e.g., Maskin et al., 2000; Blanchard and Shleifer, 2001).

Another key aspect of the central government's system of appointments of top provincial officials is cadre rotation: often, a party secretary is moved laterally to head another province at the end of his term. This practice is motivated by a desire to curb localism and break up the provincial leader's network of connections with provincial elites (Huang, 1999; Bo, 2004). Thus, even in the presence of strong career incentives, provincial leaders can be swayed away from implementing policies encouraged by the center, if their ties to the province are sufficiently strong. Such local ties limit the power of career incentives in autocracies. In this paper, we empirically investigate the limits of career concerns by analyzing whether and why party secretaries' local ties affect governance decisions.

In contrast to top-level provincial officials, such as party secretaries, who are routinely rotated between provinces, officials at lower administrative levels are allowed to rise through the ranks from low to high positions within in a single province. If a network of connections develops over time, an official who makes his career trajectory within a province can thus develop ties to lower-level elites over an extensive time period, as well as obtain a general affinity towards, or familiarity with, the province. Whereas promotions at the highest provincial level are decided solely by the center, promotions at the lower provincial levels are determined according to the "one-step management principle" (Huang, 1999): party officials at the directly superior administrative level are in charge of the lower-level promotions. Ris- 
ing from low to higher positions within a single province therefore necessitates support from other key officials at intermediate levels within the provincial hierarchy.

To measure the ties of top-level provincial officials to their provinces, we collect detailed data on the career backgrounds of all party secretaries serving in Chinese provinces from 1980 to 2005. Among all party secretaries, we identify those, who rose from low to high hierarchical levels within the province they govern; henceforth we refer to these officials as "locals," as opposed to "outsiders," namely, party secretaries who made their career shifts from low to high levels of the administrative or party hierarchy in other provinces.

First, we analyze whether a local party secretary makes different governance decisions than an outsider. We think of an outsider as solely career concerned: outsider party secretaries implement the policies that maximizes their future career prospects. Local party secretaries, in contrast, may not only be driven by career concerns, but may also have an affinity to the province or social ties to lower-level elites, which may influence their policy choices.

To analyze differences in the policies chosen by locals and outsiders, we must address the problem of reverse causality, namely, that local party secretaries may be moved elsewhere precisely to curb the development of ties to the province. We exploit variation in central leadership, that is, variation in who holds the position as the general secretary of the Chinese Communist Party (CCP). Each general secretary is interested in appointing his own close allies as party secretaries, and each general secretary is more likely to have allies in provinces where he himself worked at the early stages of his career. These two postulates yield that, when a new general secretary is appointed, provinces where the general secretary worked during his career are more likely to see a local party secretary appointed.

In addition, for an incoming general secretary, it is preferable to replace the party secretaries at the end of their five-year terms, since violating the rule can undermine the credibility of the centrally-imposed system of career incentives. The timing of expiration of the incumbents' terms is exogenous to the incoming general secretary, since the incumbent party secretaries were appointed by his predecessor. Our instrument for having a local party secretary combines the variation in the general secretary's previous work experience with the variation in the term limits of the incumbent party secretaries (who were appointed by the previous general secretary). 
We find that, despite strong career incentives, the party secretaries' career backgrounds play an important role in their governance decisions. Locals, who rose up through the administrative hierarchy inside the province they govern, have a "home bias" in their budgetary policies. Relative to outsiders, they allocate a higher share of provincial expenditure to education and health care, which results in a higher level of public goods provision, proxied by the number of primary school teachers per capita. They also allocate a lower share of provincial expenditure to investment in infrastructure, resulting in less construction output. In addition, locals raise less revenue outside the budget. As extra-budgetary revenue is positively correlated with corruption across provinces, one possible interpretation of this result is that local party secretaries are less inclined to prey on provincial business interests.

Second, to understand how these policy differences relate to the career-maximizing policy choice, we analyze how promotions of party secretaries depend on the policy outcomes that we study. We find that the promotion mechanism rewards investments in infrastructure and construction, but not investments in education and health care. This suggests that outsiders indeed adhere more closely to the career-maximizing objective than locals. Consistent with this, we show that local party secretaries are significantly less likely to be promoted than outsiders. Thus, the home bias in local party secretaries' policies has considerable career costs.

Third, we turn to the question of why local party secretaries implement different policies than outsiders, despite the fact that these policy choices depress local party secretaries' career prospects. The party secretary's career background may matter either because local and outsider party secretaries differ in their knowledge or skills; or because locals, unlike outsiders, develop an affinity to the province in general, or to its elites in particular. Better local knowledge or skills of local party secretaries cannot explain policy differences that hurt locals' career advancement, however, since better knowledge or skills are an advantage, whereas we find that local party secretaries are penalized by the promotion mechanism. Locals do have lower experience at top-level positions, which potentially could explain the difference in policy outcomes. The evidence, however, is inconsistent with knowledge or skills driving our results: the gap in policies between outsiders and locals does not close over time, as locals acquire experience at top-level positions and outsiders acquire local knowledge. Our 
leading interpretation is that the connections that locals form early in their careers are the main reason why locals choose policies different from those chosen by outsiders. While we cannot with certainty distinguish between locals having an affinity towards the population and locals having an affinity towards elites within the province, several pieces of evidence point towards the latter. First, locals do not behave similarly as those who grew up or studied in the province, which points to the fact that the home bias that we demonstrate is developed during the professional career. Second, higher intra-provincial inequality - a proxy for the gap between the preferences of elites and masses - is associated with a lower home bias in locals' spending on education and healthcare. Third, although connections to local elites hurt locals' prospects for promotions, we show that they do help in case of a dismissal, as in this case, locals are more likely than outsiders to remain in the province at a lower-level job.

Taken together, our results suggest that, from the perspective of the population, having a local party secretary is not necessarily harmful. Since education and health care were under-provided relative to construction during the 1980s and 1990s (Whiting, 1996; Luo et al., 2010), our results suggest that having a local party secretary is a substitute for local accountability (albeit highly imperfect), because locals shift expenditure towards the needs of the local population. This take-away has two implications, which we discuss in the final part of the paper. First, if the mechanism explaining the policy divergence between locals and outsiders is indeed that local party secretaries cater to the local elites, rather than develop a genuine desire to cater to the needs of the general population, then the effect of elite influence in China sharply contrasts with the detrimental role of "elite capture" found in other contexts (e.g., Bardhan, 2002; Slinko et al., 2005). Elite influence can be beneficial if some favors to the elite spill over to the general population, which happens when the gap between elites and the masses is relatively low. In our context, locals and outsiders primarily differ in their connections to elites at the lower levels of the provincial hierarchy and, thus, the home bias comes from the influence of lower-level elites. Even though elites are not representative of the masses in any context, the gap in preferences between the lower-level elites and the masses in China (particularly, in the earlier stage of transition) may be lower than in the developing and transition countries where elite influence has been shown to be detrimental for 
governance. This variation exists within China as well: a local party secretary directs more resources towards education and health care when intra-provincial inequality - our proxy for the preference divergence between elites and the masses - is low.

Our paper sheds light on the long-standing debate on the workings of federalism in the developing world. Much of this literature focuses on the career concerns among provincial leaders, created by the center through its system of promotions and demotions. ${ }^{1}$ We contribute to the strand of this literature, which considers the costs and limitations of career concerns in hierarchies. Markevich and Zhuravskaya (2011) show that high-powered career incentives work well in hierarchies with diversified and self-contained territorial divisions, whereas they induce severe negative externalities among territorial divisions when territorial divisions are inter-dependent and undiversified. Jia (2014) considers the Chinese case and shows that high-powered career concerns for provincial leaders result in higher pollution as a by-product of provincial leaders' efforts to boost economic growth. Our paper shows that incentives provided by career concerns may clash with the incentives induced by local connections and suggests that career evaluation schemes are inherently short term, which limits the set of policies that can be evaluated.

In his seminal book, Riker (1964) hypothesized that in order to realize the full benefits of federalism, the incentives facing provincial governments should stem from a combination of national career concerns and provincial accountability. Thus, the functioning Chinese federalism is puzzling since China is an autocratic state without any formal mechanisms of provincial accountability. ${ }^{2}$ Our paper contributes to resolving this puzzle by showing that local ties of provincial leaders serve, in part, as an informal institution promoting local accountability in China. ${ }^{3}$ Martinez-Bravo et al. $(2011,2012)$ find that the introduction of village-level elections, i.e., a direct formal accountability mechanism, in China also increased public goods provision.

The rest of the paper is organized as follows. Section 2 describes the career structure of

\footnotetext{
${ }^{1}$ See, for instance, Montinola et al. (1995); Maskin et al. (2000); Blanchard and Shleifer (2001); Jia et al. (2014)

${ }^{2}$ Enikolopov and Zhuravskaya (2007) tested Riker's conjecture and confirmed it by finding that fiscal decentralization results in better governance, on average, in the presence of both local elections - which provide local accountability - and strong national political parties - which provide national career concerns.

${ }^{3}$ See also Tsai $(2007 a, b)$; Huang (1999); Shih (2007) on the effects of social networks on Chinese governance.
} 
provincial party officials. Section 3 describes the hypotheses and the data. Section 4 details the empirical methodology and the construction of the instrument, and Section 5 presents the main results. In Section 6, we analyze the promotion mechanism in relation to the provincial governance outcomes that we analyze, and thus determine the career-maximizing policy. In Section 7 , we then seek to assess the mechanism. Finally, Section 8 concludes the paper.

\section{Institutional background and careers of party officials}

China has five administrative levels, illustrated in Figure A1 in the online appendix. We limit our analysis to the central-provincial level, i.e., to the two top administrative levels.

The party secretaries are the top executives in each province, with the ultimate authority and substantial discretion over provincial fiscal and regulatory policies. The substantial decentralization of economic decision-making stands in sharp contrast to the extent of political centralization. Huang (1999) describes the personnel allocation power of the center as the "ultimate trump card that the center can wield over provinces." Bo (2002) further argues that, from 1980 to 2000, the central party apparatus controlled the mobility of provincial leaders even more tightly, so as to counterbalance the fact that provincial leaders obtained more discretion with regard to economic affairs. The spirit is bluntly illustrated by the following quote, made by Jiang Zemin in 1994, at a Central Party School conference attended by provincial party secretaries: "Although you have money, the center still has the power to select and fire personnel" (Huang, 1999).

To exercise this control, the center uses an elaborate system to supervise and incentivize the provincial leaders. Party secretaries are appointed by the center for 5 years, but can be promoted or demoted at any time by the center. As mentioned above, Chen et al. (2005) and Li and Zhou (2005) show that the main criterion for promotion and demotion of provincial leaders is economic growth relative to the average performance across provinces and to the provincial performance under the predecessor. Jia et al. (2014) document that personal connections of provincial leaders to the central government serve as a catalyzing factor in career concerns: provincial leaders with central connections face a stronger relationship between economic performance of their provinces and their promotion prospects. In addition, party 
secretaries are often rotated to an equivalent position in another province. Bo (2004) states that, starting in the 1980s, these rotations became instrumental for ascertaining the party secretaries' loyalty toward the center. ${ }^{4}$ In particular, rotation was employed to break the social ties that could emerge between the provincial leadership and special interests in the province, since "as joint tenures lengthen, local officials may come to share more common interests" (Huang, 1999). The director of the Department of Organization (DOO) Lu Feng explicitly stated in 1991 that breaking up the local "network of connections" was one principal reason for making rotation a standard administrative practice (Huang, 1999). Another closely related reason is to reinforce an official's identification with the center rather than with the local community (Edin, 2003).

At lower levels of government, both rotation practices and appointment procedures are different. First, party officials are not promoted by the center. Instead, (re)appointment decisions are governed by the "one-step management principle" (Huang, 1999). According to this principle, both evaluation of cadre performance and (re)appointment decisions are made by cadres one hierarchical level above the cadre who is subject to evaluation. At lower levels, a party official is thus dependent on his direct superiors in rising to the next hierarchical level. Second, while cadre rotation may occur also at lower levels, the practice is more infrequent, less institutionalized, and seldom rotates the official between provinces (Edin, 2003). Thus, in practice officials are allowed to rise through the ranks from low to high positions within in a single province. During the process through which an official reaches the party secretary position, while rising through the ranks, he can spend considerable time within a single province, enabling the development of ties to low-level elites, as well as a general affinity to the province. We refer to a party secretary with this type of career background, that is, who worked at low and high hierarchical levels within the province that he governs, as a "local" party secretary.

\footnotetext{
${ }^{4} \mathrm{Bo}(2004)$ also discusses the fact that, in addition to requiring economic growth and loyalty from party secretaries, the center does expect provincial leaders to pay attention to local conditions and notes that "in this regard, governors and vice governors are more relevant."
} 


\section{Hypotheses and the Data}

\subsection{Hypotheses}

Just like politicians in a democracy face strong career incentives to implement policies that are desired by the voters, high-level officials in an autocracy can be given strong career concerns to choose a particular policy mix, by linking the officials' future promotion prospects to its implementation. Given that the Chinese party secretaries are faced with high-powered career incentives (discussed in Section 2 above and further in Section 6 below), we would expect a party secretary who is solely career concerned to implement the policies that maximize his future career prospects. We hypothesize that outsider party secretaries are uniquely career concerned, and thus implement the career-maximizing policy mix. Local party secretaries, in contrast, are not only be driven by career concerns, but also place some weight on other, additional objectives. These additional objectives may stem either from an affinity towards the province and its inhabitants, or from ties to lower-level provincial elites, or both.

If locals have such additional objectives, then career concerns would only have a limited incentive effect on local party secretaries. Consequently, locals would implement policies that, intuitively, are some "weighted average" of the policy mix encouraged by the promotion mechanism, on the one hand, and the policies desired by the provincial inhabitants, or the provincial low-level elites (depending on the nature of the local party secretary's additional objectives), on the other.

If locals and outsiders have different objectives, as we postulate, then we should observe that locals and outsiders implement different policies. The nature of this policy divergence, however, depends on the local party secretaries' additional objectives. If locals have an affinity to the population, then we would expect locals to deviate from the career-maximizing policies in a way that benefits the population (in Section 7.4 we discuss why the center may encourage policies that are not socially optimal). If locals instead have ties to low-level elites, then locals will deviate from the career-maximizing policies in a way that benefits the elites. The nature of this divergence, in turn, depends on the preferences of these elites.

In Section 7 below, we empirically analyze whether locals and outsiders likely differ in their affinity to the province, or in their connections to lower-level elites; for now, however, we 
remain agnostic, and simply examine whether locals' and outsiders' policy choices differ. In Section 7 , we also discuss several other mechanisms that could give rise to differences between locals' and outsiders' policy choices. In particular, they could face different constraints, for example by having different information sets, abilities, or by being subject to different monitoring intensities. Such constraints only matter, however, if they constrain the party secretary's ability to implement the career-maximizing policy. Indeed, so long as both locals and outsiders are able to implement the career-maximizing policy mix, any deviations from this mix must stem from a multiplicity of objectives: if the official was solely career concerned, he would implement the policies that maximize his promotion probability.

To summarize, our hypotheses have several testable implications. First, the policies of local and outsider party secretaries should systematically differ. Second, local party secretaries should have a systematically lower probability of promotion. Third, if local party secretaries cater to local elites rather than to the local population, then the size of the preference gap between provincial elites and the population should matter for whether the local population benefits from the policies implemented by local party secretaries.

\subsection{Data and measurement}

We collected panel data for 30 province-level units (all except Tibet) for 26 years, from 1980 to 2005 , resulting in 755 province $\times$ year observations. ${ }^{5}$

\subsubsection{Backgrounds and careers of provincial party secretaries}

During our sample period, 160 individuals served in 180 provincial party secretaries positions (spells). For each party secretary, we record whether he, prior to assuming the current position, i) worked in the central government or in central party organs, ii) worked in other provinces, and iii) worked in the same province. For each of these prior work experiences, we distinguish between low-level and high-level positions. We follow Li and Zhou (2005); Chen et al. (2005) and define a high position in the center as deputy minister or higher, and a high position in a province as deputy governor or higher. A low position in a province

\footnotetext{
${ }^{5}$ Tibet differs significantly from the other provinces in terms of political instability and ethnic composition. Data on Hainan start from 1988, when it was separated from Guangdong province. Data on Chongqing start from 1997, when it was separated from Sichuan province.
} 
is defined as any position that is not a high one; thus, the coding does not allow us to distinguish exactly what low-level position an official holds. We also record their places of birth and study, year of birth, and level of education. In addition, for each point in time, we record the party secretary's tenure on the job. Finally, for each outgoing party secretary, we have information about the reason for leaving office, i.e., if the party secretary retired, was promoted or demoted, or passed away.

The party secretaries spent between one and twelve years in office, and their career backgrounds vary substantially. Of the 180 party secretary positions, $35 \%$ were held by locals, i.e., by individuals who worked at low and high positions within the province $(38 \%$ of the 755 province $\times$ year observations). While we do not know exactly what low-level position the official had held, being local captures the fact that the PS served with lower-level officials within the province he governs, and successfully transitioned to higher positions. As we discussed in Section 2, making a transition from low to high positions within a province requires the support of provincial elites (i.e., representatives of the local administrations, party organs, bureaucrats, and top management of state owned enterprises and large collectives): elites are responsible - both formally and informally - for nominations to high- and appointments to medium-level positions in the administration and state-owned enterprises of the province (Bo, 2004). Approximately half of the local party secretaries - or $19 \%$ of all party secretaries - were never rotated to the center or another province before assuming the position as party secretary. We refer to a party secretary who is not local as an outsider. Of all party secretary positions, $65 \%$ were held by outsiders ( $62 \%$ of the observations).

The distinction between locals and outsiders refers to the official's career background, and not to his place of birth or study. We refer to secretaries who were born or studied in the province as native. ${ }^{6}$ Native party secretaries held $12 \%$ of the positions $(14 \%$ of the observations). Among native party secretaries, $24 \%$ rose from low to high positions in other provinces. Out of the non-native party secretaries, $30 \%$ are locals. Table 1 summarizes the backgrounds of the individuals holding the 180 party secretary positions, overall as well as separately for locals and outsiders. Panel A of Table A1 in the online appendix presents summary statistics for the 755 province $\times$ year observations.

\footnotetext{
${ }^{6}$ We discuss the definition of this variable further in Section 4.
} 
Our main variable of interest, a dummy which takes the value of one if the party secretary is local in a given province and year, varies greatly within provinces. There are only four provinces (Chongqing, Guizhou, Hainan, and Inner Mongolia) where there is no temporal variation and only outsiders served as party secretaries; in all other provinces, both locals and outsiders served as party secretaries at different times. We also collect information on the career backgrounds of the individuals serving as China's supreme leader, the general secretaries of the Chinese Communist Party (CCP), during our sample period. Information on the biographies of the officials - place and year of birth, place and level of studies, career paths, and current affiliations - was collected from various sources, many of which are in Mandarin Chinese. The main sources are The People's Daily, the web site Chinavitae.com, and the web site of the Center for China Studies at the NCCU in Taipei, Taiwan. ${ }^{7}$ We also used the official government portal of the Government of the People's Republic of China, www.gov.cn and, occasionally, other web resources. Information on the reasons for discontinuing the party secretary position was obtained from Chen et al. (2005). ${ }^{8}$

\subsubsection{Policy outcomes and additional data}

As policy outcomes, we consider available measures of public goods provision and infrastructure investment, as well as an (imperfect) measure of rent extraction.

First, we aim at capturing the main tradeoff in provincial budgetary policy - whether to spend the marginal yuan of budgetary revenue on investment in infrastructure such as roads, railroads, and construction of commercial real estate, or on public goods such as education and health care. For this purpose, we look at the composition of provincial budget expenditure. In particular, we are interested in the share of provincial public expenditure allocated to public goods provision such as education and health care. The data are available only for large expenditure categories. In particular, we consider the category of expenditure

\footnotetext{
${ }^{7}$ The Center's website is http://ics.nccu.edu.tw/neweb/eng/index.php.

${ }^{8}$ In some cases, different sources provided conflicting information. Conflicting information most often concerned the start or end month of a party secretary spell, though this was immaterial in all but a few cases (of 180), since we assign a party secretary to a province for all years for which he serves for six months or longer. For these three spells, as well as spells where bibliographical information differed (e.g. a discrepancy in educational attainment for one spell), we use the information provided in the majority of sources. Finally, not all sources did contain information about all officials' complete career paths; when information was available from only one source, we used this source.
} 
on education, healthcare, culture, and science as public goods spending, and henceforth refer to this variable as social spending. We also have data on the following expenditure categories: capital construction, innovation, agricultural subsidies, and administrative expenditure.

We also consider the following real outcomes of spending on public goods: log of the number of teachers in primary school, and log of total construction output.

Finally, we use the size of provincial extra-budgetary revenue (EBR) as a rough proxy for extraction of ad hoc fees from local businesses. In contrast to budgetary revenue, EBR is collected through informal fiscal practices, outside of the official taxation system, by imposing administrative and regulatory charges on enterprises and taxpayers (World Bank, 2002). Several authors (e.g., Ma et al., 2003; Zhan, 2009) argue that EBR is an indication of excessive taxation and bribe extortion of local business. According to a World Bank report (World Bank, 2002), the fees are generally designed to tap "deep pockets," with enterprises as prime targets. Among enterprises, the rural and export-oriented sectors are particularly important sources of extra-budgetary revenue (Zhan, 2009). ${ }^{9}$ This suggests that provincial EBR could potentially serve as a coarse indicator of over-regulation of provincial business and predatory behavior of provincial governments towards local businesses. However, EBR could also be just another source of non-shared revenue which is used for public goods provision (Bird and Wong, 2005). Thus, to get a better understanding of whether EBR could capture predatory regulations and petty corruption, we examine how it correlates with two province-level measures of provincial anti-corruption efforts used by Cole et al. (2008): an anti-corruption score and an efficiency of government score. These measures are available at the province level for the years 1998 to 2003. The over-time within-province variation in these measures is very small, however; and the meaningful variation is across provinces. Thus, we take their over-time averages and relate them to over-time averages of EBR over the same time period. As displayed in Figure A2 and Table A2 in the online appendix, EBR is negatively and significantly correlated with anti-corruption effort and negatively (and almost significantly) correlated with provincial government efficiency, conditional on initial population and GDP.

\footnotetext{
${ }^{9}$ Even though EBR is raised both at the provincial and sub-provincial levels, Zhan (2009) argues that lower-level governments cannot collect EBR at will as they are constrained by intervention from province-level officials. Thus, in addition to the direct control over extra-budgetary revenue collected at the provincial level, the provincial leadership indirectly influences the collection of such funds at lower levels.
} 
This evidence supports the view that the variation in the size of EBR may actually proxy for the variation in corruption and overregulation of local business. ${ }^{10}$ The reason why EBR is superior to any other existing proxy, despite being highly indirect and crude, is that it varies over time and is available for a relatively long period of time, from 1982 to 2003 (and for some provinces from 1980). All outcome variables are summarized in Panel B of Table A1, and exact definitions and sources of each variable are given in Table A3 in the online appendix. Throughout our analysis, we also use a number of other variables, summarized in Panels C and D of Table A1, which we describe further as we use them. Unless otherwise noted, the data come from various publications of the National Bureau of Statistics of China, and monetary variables are expressed in 1978 real terms. Data on the fiscal revenue-sharing contract between the center and the provinces, discussed in Section 4, was obtained from Jin et al. (2005).

\section{Empirical methodology}

Our first task is to estimate the causal effect of having local vs. outsider party secretary on governance. We estimate the following panel fixed effects equation:

$$
\text { Outcome }_{p t}=\alpha \text { Local }_{p t}+\beta^{\prime} X_{p t}+\phi_{p}+\tau_{t}+t \xi_{r}+u_{p t},
$$

where $p$ indexes provinces, and $t$ indexes years. Outcome $e_{p t}$ is a policy outcome; Local $l_{p t}$ is our main explanatory variable, a dummy for local party secretary. $X_{p t}$ is a vector of observed attributes of province $p$ at time $t$ that directly affect Outcome $e_{p t}$. Province and year fixed effects, $\phi_{p}$ and $\tau_{t}$, control for all time-invariant differences between provinces and regioninvariant changes over time, respectively. To account for the divergent development trends between different territories in China, we also control for linear trends specific to each of the six economic regions: East Coast, South Coast, North Coast, Central Core, Hinterland, and Far West. Figure A3 in the online appendix presents the map and the depicts the six economic

\footnotetext{
${ }^{10}$ This is consistent with official rhetoric. For example, in the words of Yu Guangyuan, of the Budgetary Work Commission of China's legislature, "a lack of effective regulations [of extra-budgetary revenue] means the improper use of such funds has become a hotbed for illegal activities and corruption." See http://english.peopledaily.com.cn/200606/17/eng20060617_274814.html.
} 
regions as well as trends in the real per capita rural income and household consumption for each of the regions.

If the career background of party secretaries affects the policy outcomes, then $\alpha \neq 0$. Two challenges arise in causal estimation of $\alpha_{1}$. First, the covariates $X_{p t}$ must account for the potential confounds which may affect outcomes and are correlated with Local $_{p t}$. In particular, we need to control for the provincial leaders' fiscal incentives and characteristics that affect promotion prospects, beyond our policy outcomes. Second, Local ${ }_{p t}$ may itself depend on outcomes, giving rise to reverse causality. As discussed above, the center may be more likely to appoint outsiders in provinces where it suspects particularly close ties between business interests and the provincial leadership, for example. Below we describe how we address each of these challenges.

\subsection{Covariates: accounting for incentives}

A large literature studies how the fiscal and political incentives of provincial leaders, designed by the center, affect the party secretaries' performance. In order to estimate the effect of the provincial leader's career background on policy outcomes, we need to account for variation in these incentives.

First, until 1993, each province had its own fiscal revenue-sharing contract with the central government. Oi (1992) and Montinola et al. (1995) (among others) argue that these revenuesharing contracts made provincial governments residual claimants to a certain part of the marginal tax collection and were key to providing provincial leaders with "fiscal incentives" to generate revenue. Jin et al. (2005) have shown that the strength of these fiscal incentives can be characterized by the Marginal Retention Rate (MRR) of budgetary revenue, and that the MRR was correlated with growth-promoting reforms in the Chinese provinces. The MRRs vary both over time and across provinces. We control for differences in fiscal incentives by including MRR as a covariate.

Second, we must control for characteristics that affect the promotion probability (other than our governance outcomes) since they may influence the resolution of the tradeoff between career concerns and other objectives in the utility function of the provincial leader. As we described in Section 2 above (and further discuss in Section 6 below), Li and Zhou (2005) and 
Chen et al. (2005) have demonstrated that the probability of promotion of a provincial leader is tied to provincial economic performance. We therefore control for the average provincial growth during the party secretary's tenure up to time $t$, and for the average provincial growth under the predecessor. Following the literature on career concerns, we further control for (i) the secretary's age; (ii) a dummy for the last term in office before retirement, which captures the fact that party secretaries can no longer be promoted or reappointed after they reach the age of 65; (iii) tenure; (iv) whether the secretary has previous work experience in high positions in the center; (v) the secretary's level of education; and (vi) whether the secretary serves a second term. ${ }^{11}$ Many of these variables may also affect governance decisions directly, and not only through their effect on career concerns. For example, a party secretary's experience may have a direct effect on his policy choices, which implies that age, tenure on the job, and level of education may play important roles in explaining differences in provincial policies.

In addition, we control for logarithms of population, urbanization, and lagged gross provincial product, as all of these variables may also directly influence the outcomes. We also control for whether the party secretary concurrently holds a seat in the Politburo, which Huang (1999); Liu (2010) refers to as a "concurrent" appointment, as well as for whether the secretary is native to the province (i.e., was born or studied where he serves). ${ }^{12}$ Panel $\mathrm{C}$ of Table A1 in the online appendix presents summary statistics for all control variables.

\subsection{Instrument for Local}

An important challenge in estimating $\alpha$ is endogeneity, which arises if there are unobservable provincial characteristics that both affect the outcomes and are correlated with whether

\footnotetext{
${ }^{11}$ The "last term" indicator takes the value of one when the secretary is 60 years old or older, i.e., this dummy switches on at the start of the official's (last) five-year term. The rule instigating retirement at the age of 65 was enforced starting 1990; hence, this variable takes the value of zero until 1990. Using a dummy for over age 65 as in Li and Zhou (2005) does not change our results, though this variable has lower explanatory power than our "last term" dummy.

${ }^{12}$ One concern with controlling for native is that the secretaries who were born before the end of the war (i.e., before 1949) have a weaker attachment to the native province. If so, the native dummy does not accurately capture the average effect of a party secretary being native to a province. In order not to underestimate the impact of being native, we record a party secretary as born in the province if and only if he was born in the province after 1949; though we have replicated the analysis recording a secretary as native also if her was born before the end of the war, and found that the results (available upon request) do not change, though this variable has less power.
} 
a local or outsider is appointed as party secretary. Endogeniety also arises if the policy outcomes affect whether a switch between a local and outsider occurs. For instance, the probability that an outsider is appointed to replace a local party secretary may be higher in provinces where local corruption is rampant. To address this concern, we need an instrument for Local $_{p t}$ : a variable that affects the probability that a local party secretary replaces an outsider (and vice versa) in a given province at a given point in time, but that does not have a direct effect on the outcome variables. For this purpose, we exploit two sources of variation. First, we use variation in central leadership, that is, variation in who holds the position as the general secretary of the Chinese Communist Party (CCP). Intuitively, since the provincial party secretary positions are of crucial political importance, each general secretary prefers to appoint officials whom he personally trusts to these positions. Each general secretary is more likely to have allies in provinces where he himself worked at the early stages of his career. Therefore, when a new general secretary is appointed, provinces where the general secretary worked during his career are more likely to see a local party secretary appointed.

During our sample period, 1980-2006, there were three general secretary switches. Zhao Ziyang replaced Deng Xiaoping in 1987, Jiang Zemin replaced Zhao Ziyang in the end of 1989, and $\mathrm{Hu}$ Jintao assumed the position in 2003. ${ }^{13}$ These general secretaries had work experience in different provinces: Deng Xiaoping worked in Beijing, Jiangxi, Guangxi, and Sichuan; Zhao Ziyang served in Inner Mongolia, Guangdong, and Sichuan; Jiang Zemin worked in Beijing, Hubei, Jilin, and Shanghai; and Hu Jintao worked in Beijing, Guizhou, and Gansu (and Tibet, which is not in the sample). To capture this variation, we construct a dummy variable, GsWork $k_{p t}$, indicating that the current general secretary, who is in power at time $t$, has previous work experience in province $p$.

Second, we combine the variation in the general secretary's work experience with variation in party secretary term limits. The logic behind this relates to an incoming general secretary's incentives to appoint new party secretaries. Ideally, an incoming general secretary would like

\footnotetext{
${ }^{13}$ Formally, Deng Xiaoping never served as the general secretary; he was the chairman of the Central Military Commission. However, there is considerable evidence that he was the de facto leader of China holding all real powers until at least 1987, and possibly also during Ziyang's tenure. For this reason, we have replicated our entire analysis with an instrument using Deng Xiaoping instead of Zhao Ziyang during 1987-1989. All results are robust to using this alternative instrument with the only difference that the instrument treating Zhao Ziyang as a separate leader during 1987-1989 gives a better fit in the first stage, presumably, because it has more variation. These results are available upon request.
} 
to instantly replace all party secretaries by his own allies. But although he may replace party secretaries at any point in time, it is costly to make replacements before the end of the party secretaries' five-year terms: systematic violations of the five-year rule weaken the center's commitment to the stated promotion mechanism, and hence the party secretaries' career concerns. If an incoming general secretary cannot instantly replace all incumbent party secretaries, he must use a gradual approach. Our instrument relies on the idea that, when he chooses the order of replacements, he effectively weighs the cost of violating the fiveyear rule with the benefit of replacing each incumbent party secretary. More specifically, we postulate that it is more urgent for an incoming general secretary to replace the incumbent party secretary in provinces where the general secretary has no previous work experience. Intuitively, the general secretary wants to know people in the top provincial leadership in all provinces; and this is less likely, in provinces where he did not work.

We can exploit the five-year terms because, when the new general secretary assumes his position, the incumbent party secretaries are at different stages of their five-year terms. ${ }^{14}$ This variation in timing of expiration of the incumbents' terms is exogenous to the incoming general secretary, since the incumbent party secretaries were appointed by his predecessor. To capture this variation, we create a dummy $T_{p t}$, where $T$ stands for "transition" period between two consecutive general secretaries. This dummy equals one if the five-year term of the incumbent party secretary, who is in power in province $p$ at the time of the current general secretary's arrival, is not yet over in year $t$. Put differently, a province is in a transition period when a new general secretary has assumed power, but the incumbent party secretary's five-year term has not expired, and hence, he cannot be easily replaced. ${ }^{15}$

Combining the variation from the general secretaries' work experience and the party secretary term limits yields the following approximate appointment rule for local vs. outsider party secretaries:

$$
Z_{p t}=\left(1-T_{p t}\right) G s W o r k_{p t}
$$

Outside of the transition period $\left(T_{p t}=0\right)$, the incumbent party secretary's term has expired, and the general secretary can appoint his allies as party secretaries. Then, the

\footnotetext{
${ }^{14}$ Figure A4 in the online appendix shows the distribution of the starts of party secretaries terms over time.

${ }^{15}$ The term limit was instigated in 1982; hence, for Deng Xiaoping we let $T_{p t}=0$ in 1980 and 1981 in the four provinces where he previously worked.
} 
appointment mechanism is captured by GsWork: provinces where the general secretary worked are more likely to see a local party secretary appointed. During the transition period $\left(T_{p t}=1\right)$, we must distinguish between provinces where the general secretary worked, and where he did not. In provinces where the general secretary worked, he waits for the incumbent party secretaries' five-year terms to expire. In provinces where he did not work, in contrast, he does not wait for the incumbent party secretary's term to expire, but immediately reshuffles them.

Our resulting instrument $Z_{p t}$ varies both across provinces and over time. There is intraprovince variation over time in 7 provinces (Beijing, Jilin, Shanghai, Jiangxi, Hubei, Guangxi, and Sichuan). $Z_{p t}=1$ in 76 province $\times$ year observations. The construction of the instrument is illustrated by the following example. Before Jiang Zemin became the general secretary, he had worked in the province of Jilin. All general secretaries before Jiang Zemin had no work experience in Jilin, thus, the instrument takes the value of zero in Jilin in all years before Jiang Zemin assumed power. When Jiang Zemin came to power in 1990, Jilin's incumbent party secretary had only been in place for two years. We therefore expect him to wait for the expiration of this incumbent party secretary's 5-year term before replacing him. Thus, the instrument takes the value of zero in this province in the years 1990-1992, corresponding to the facts that the incumbent party secretary is expected to stay in his place till his term expires. During the period of 1993-2002, the instrument takes the value of 1 , as the transition period is over and Jiang Zemin is expected to appoint a new party secretary in Jilin who is his close ally. Due to Jiang Zemin's previous work experience in Jilin, this party secretary is more likely to be local. ${ }^{16}$

If the outlined logic for the appointment rule of local vs. outsider party secretaries is a good approximation of the reality, $Z_{p t}$ should positively affect the probability that the party secretary in province $p$ at time $t$ is Local. Our first stage, therefore, is the linear probability

\footnotetext{
${ }^{16}$ The instrument reflects the five-year rule for the length of the appointment term regardless of whether the general secretaries respected this rule or not. This is because, for an incoming general secretary, the set of incumbent provincial party secretaries, and their term limits, are exogenous; this structure was put in place by their predecessor. However, whether a new-coming general secretary decides to violate a five-year rule is not exogenous.
} 
model of appointing a Local party secretary:

$$
\operatorname{Local}_{p t}=\rho Z_{p t}+\gamma^{\prime} X_{p t}+\phi_{p}+\tau_{t}+t \xi_{r}+v_{p t}
$$

where all of the notation is as above.

An important question for estimating equations (1) and (3) is what the correct set of assumptions about the variance-covariance matrices is. First, one should expect the error terms to be non-independent over time within each province. Thus, one of the two relevant dimensions for clusters in error terms is provinces. In addition, our baseline specification allows for a second dimension of clusters, which mimics the variation that we exploit in our instrument. Intuitively, if the general secretary differentially affects the provinces where he did and did not previously work - for example, when it comes to promotion decisions, as in our instrument - then this may induce a correlation of error-terms separately within the group of provinces, where the general secretary worked, and within the group of provinces, where the general secretary did not work before. General secretaries are (re-)appointed by the CCP Congresses, the main political events in China. The congresses took place in 1982, 1987, 1992, 1997, and 2002 during our observation period. Combining the general secretaries tenures' (-1986, 1987-1989, 1990-2002, 2003-) with CCP Congress spells yields two spells during Xiaoping's tenure (before 1982, 1982-1986), one spell during Ziyang's tenure (19871989), three spells during Zemin's tenure (1990-1991, 1992-1996, 1997-2002), and one spell during Jintao's term (after 2002). Within each of these seven spells, we allow the error terms to be correlated within two groups of provinces - where the general secretary had, and did not have, previous work experience, respectively. Our baseline specification thus uses twoway non-nested clustering along these two dimensions, with 30 and 14 ( 7 spells $\times 2$ groups of provinces) clusters, respectively. ${ }^{17}$

Table 2 presents the results of the first stage. In column one, there are no covariates except for province and year fixed effects and economic-region-specific time trends, which

\footnotetext{
${ }^{17}$ As this logic produces only few clusters, the standard errors using this two-way non-nested clustering method could be downward biased (Cameron et al., 2008). Therefore, for robustness we present the results with alternative ways of clustering. In particular, we present our baseline OLS, IV and reduced form results with one-way clustering at the province level and our baseline OLS and reduced form results with clustering at the province level with wild bootstrapped standard errors (Cameron et al., 2008).
} 
are included in all specifications. Column two adds individual characteristics of the party secretaries as covariates. Province-level controls are used in column three. The full set of covariates, i.e., all controls used in the first three columns, is included in column four. Our instrument is a strong and significant predictor of the probability that a party secretary is local, in all specifications. When the instrument switches from zero to one in a province, the probability that the party secretary is local increases by 41 percentage points according to the specification with the full set of controls (column 4). The last two rows in the table present two sets of F-statistics for the excluded instrument from estimating the first stage under the two alternative assumptions about the correlation among error terms: with two-way clusters, i.e., our baseline specification, and with robust standard errors. When the full set of controls is included (column 4), the F-statistic with two-way clusters is above the conventional level of 10 ruling out concerns about a weak instrument problem. ${ }^{18}$

\subsubsection{Excludability of the instrument}

An important identification assumption is that our instrument affects outcomes only by means of affecting the probability that the party secretary is local. This exclusion restriction is not testable directly, but indirect evidence can be provided in support of this assumption. The main concern is that a general secretary may treat provinces where he previously worked differently also in other respects, in addition to appointing party secretaries differently. In particular, one may worry that general secretaries favor those provinces over the ones that they are not familiar with. We consider three measurable ways, in which the central government can give preferential treatment to a particular province over others: (i) before the fiscal reform of 1994, provinces could receive a higher Marginal Retention Rate (MRR) for their revenue, which gives a province more fiscal autonomy; (ii) after the fiscal reform of 1994, a province could receive a higher intergovernmental fiscal transfer, which has a significant discretionary component, and thus, the central government potentially can increase the

\footnotetext{
${ }^{18}$ We cannot apply the Stock-Yogo threshold directly to gauge whether we have a weak instruments problem, because it is calculated for the case with uncorrelated error terms, which is not a correct assumption in our case. The F-statistic obtained using such an assumption is 33 with the full set of controls as reported in the last row of the table, which is higher than the Stock-Yogo weak ID test critical values (16.38 and 8.96, at $10 \%$ and $15 \%$ maximal IV size, respectively.) However, our baseline assumption about the correlation among error terms, i.e., two-way clusters, is much more conservative.
} 
provincial budget at will; and (iii) the provincial party secretary could be appointed to the Politburo of the CCP, which gives the province additional power in lobbying for redistribution of central funds, e.g., for getting central investment projects. We analyze whether these outcomes are related to our instrument.

Table 3 presents the results of regressions with pre-1994 MRR (columns 1-2), post-1994 net central transfers to the province (columns 3-4), and Politburo membership of the party secretary (columns 5-6) as dependent variables. We relate these outcomes to a dummy for whether the general secretary worked in the province (Panel A) and to our instrument, $Z_{p t}$ (Panel B) ${ }^{19}$ Additional covariates are as in columns (1) and (4) of Table 2: no controls except province and time fixed effects, and all controls. In addition, we include a dummy for whether the general secretary was born or studied in the province.

In these regressions, neither our instrument nor general secretary's work experience is statistically significant in any regression. While this evidence does not prove our instrument excludable, it provides a reassuring reality check as it suggests that previous work experience does not constitute a basis for favoritism on the part of central leaders. ${ }^{20}$

\section{Results: Career backgrounds and policy}

\subsection{Baseline results}

Local and outsider party secretaries make systematically different policy choices. Table 4 presents our baseline results. We present the results for each policy outcome using the full set of controls. Panel A presents the OLS results; Panel B - the 2SLS results; and C - the

\footnotetext{
${ }^{19}$ As explained above, in addition to the general secretary's work experience, the instrument takes into account the timing of the term expiration for party secretaries, who were in place at the time of the change in central leadership. If a general secretary treats provinces where he worked previously differently, he may be expected to do so regardless of whether the term limit of the incumbent party secretary expired or not.

${ }^{20} \mathrm{An}$ important drawback of our instrument is that it has within-province variation only in seven provinces. Thus, 2SLS regressions result in a causal estimation of the effect of local specific to this subpopulation. In Table A4 in the online appendix, we show how the observable characteristics of the "compliers" to our instrument differ from the population. Compared to the average observation in the sample, compliers are slightly less likely to have higher education or to have worked in the central government, and are less likely to have a seat in the Politburo. Because our 2SLS estimates reflect the particulars of the complier group, which is different from the average observation, the 2SLS results may differ from the OLS results even in the absence of an endogeniety problem (we discuss this further in Section 5 below). In what follows, we estimate equation (1) with OLS and with 2SLS using $Z_{p t}$ as the instrument for $L_{o c a l}$, in addition, we report results of the reduced form specification, in which we relate our outcomes of interest directly to our instrument.
} 
reduced form.

First, we address the question of how the composition of the provincial budget and public goods provision is affected by having a local party secretary. Column (1) presents results for the share of social expenditure. The OLS, IV, and reduced form results all point to a significantly larger spending on these public goods by locals than by outsiders. A local party secretary spends on average 3.5 percentage points more of their budgets on social expenditure than outsiders do according to the IV estimate. This is a large effect since on average a quarter of the budget spending is directed to social expenditure. The point estimate in the OLS regression is smaller in magnitude, but also economically significant, i.e., 1 percentage point. (We discuss the differences in OLS and IV estimates below.)

Column (2) presents results for the number of primary school teachers. Again, all three specifications, the OLS, IV, and reduced form, yield that when a local party secretary heads the province, the number of primary school teachers significantly increases. This suggests that local secretaries' higher social spending translates into actual improvements in public goods provision. The magnitude is as follows: if a local party secretary replaces an outsider, the number of primary school teachers increases by $9 \%$ according to the IV estimate. The magnitude of the corresponding OLS estimate is $1.7 \%$.

An important question is which categories of public spending decrease as a result of an increase in the share of social spending by local party secretaries. None of the categories that we have data for (other than social expenditure) are significantly affected by Local when we consider each category individually. Yet, the share of the sum of capital construction, administrative expenditure, and investment and innovation expenditure - which represent all the big categories of spending except agricultural subsidies - is significantly lower for local party secretaries. In regressions of the share of agricultural subsidies, the coefficient on Local is positive but insignificant. ${ }^{21}$ These results suggest that in provinces governed by a local party secretary, spending on public goods increases at the expense of government construction and infrastructure investment. Column (3) of Table 4 confirms this conjecture; it reports the results for the total output of construction enterprises. In all specifications,

\footnotetext{
${ }^{21}$ We do not report these results here in order to save space. The share of the sum of capital construction, administrative expenditure, and investment and innovation expenditure is almost an increment to the share of social expenditure, results on which we present. These results are available from the authors upon request.
} 
construction output in a province is significantly lower under the leadership of a local than an outsider party secretary. According to the IV estimate, the provincial construction output is $32 \%$ lower with local party secretary at the helm of the province. The OLS regression yields a $7.7 \%$ average difference in the construction output between local and outsider party secretaries. The decrease in construction cannot be explained by the fact that the local party secretaries raise less revenue (EBR), which is the case, as we show below. The coefficient on Local in Column (3) remains negative and significant when we control for the size of total budgetary revenue or for the sum of total budgetary and extra-budgetary revenue.

Column (4) presents results for the effect of having a local party secretary on the size of extra-budgetary revenue. Locals raise significantly less EBR. The magnitude is as follows: if a local party secretary replaces an outsider, EBR decreases by $51.5 \%$ according to the IV results and $6.6 \%$ according to the OLS results. The IV results suggest that an outsider party secretary, on average, collected additional EBR amounting to $8 \%$ of budgetary revenue. ${ }^{22}$ Under the assumption that EBR proxies for the level of predatory regulation of, and rent extraction from, local businesses, these results suggest that local party secretaries are less predatory towards business than outsiders are, by imposing fewer discretionary administrative fines, levies, and charges.

For all outcomes, the IV estimates are much larger in magnitude than the OLS estimates. This may be explained by 1) endogeneity bias in the OLS regression, 2) an attenuation bias due to substantial measurement error in the main explanatory variable, or 3) by the particulars of the complier group. To shed light on what is driving this difference, we reestimated our OLS regressions on the sub-sample of provinces with variation in the instrument (results available from the authors upon request). While the magnitude of the OLS results on social spending and the number of teachers in the reduced sample is similar to the ones in the full sample, the magnitude of the OLS estimates for construction output and EBR are much larger and, thus, much closer to the IV estimates: $20 \%$ for construction and $18 \%$ for EBR. The remaining gap between IV and OLS estimates comes either from the measurement error or from endogeneity in the OLS estimates. Both sources of bias are possible. The measurement error arises from the fact that Local is just a characteristic of the career path of

\footnotetext{
${ }^{22}$ If we control for the total provincial budgetary revenue, the results are essentially unchanged: the OLS coefficient is -0.0646 , and the IV coefficient is -0.504 , with significance levels unchanged.
} 
the party secretary, while it is supposed to measure the tightness of the relationship between the secretary and the province. Whether a party secretary is promoted locally is a noisy proxy for how close the preferences of the party secretary are to those of the the provincial elite or provincial population. This measurement error can be substantial, as closeness to the provincial elite or population depends on many factors that are unrelated to career histories of the party secretaries in addition to whether party secretaries are local. The endogeneity bias may arise because the center can be strategic in appointing local and outsider party secretaries depending on local conditions. ${ }^{23}$

Overall, we find that local party secretaries spend more on public goods such as health care and education, and provide more public goods, at the expense of government construction. Moreover, the evidence suggests that locals are less predatory towards local business. ${ }^{24}$

\subsection{Testing for pre-trends}

The analysis of the previous section can be interpreted as causal inference in the absence of pre-trends, namely, that the outcomes do not start to diverge before the appointment of locals or outsiders. To rule out such pre-trends, we must compare outcomes in provinces

\footnotetext{
${ }^{23}$ In addition to our baseline set of explanatory variables, we also estimated specifications, controlling for various individual characteristics and, in particular, the career background of the provincial governor, the head of the provincial government and, arguably, the second most important person in the province after the party secretary. We found that the governor's characteristics have no significant association with the considered provincial policy outcomes. This evidence is consistent with the view that the party secretary is the top executive in the province, who holds the ultimate authority over the decision about allocation of spending to public goods provision or infrastructure.

${ }^{24}$ To establish robustness of our results, in Table A5 we also present $p$-values from OLS, IV and reduced form models using one-way clustering at the province level, as well as from OLS and reduced form models using one-way clustering with wild bootstrapped standard errors (Cameron et al., 2008). Clustering at the province level yields $p$-values that are very similar to those obtained with two-way clustering. Using the wild cluster bootstrap generally raises the $p$-values: they slightly exceed 0.1 in the OLS regressions for teachers and construction. In the reduced form specifications, however, the coefficient on local remains statistically significant at the five percent level for all outcomes except teachers, which is insignificant, but very close to the conventional significance level with $p$-value equal to 0.1201 . Thus, while our result for teachers is somewhat sensitive to whether or not we use the wild cluster bootstrap, our results generally are robust to multiple ways of clustering. We also tried estimating the effects controlling for 30 province-specific linear time trends instead of 6 economic-region-specific time trends. There is too little variation in the data to allow for a 2SLS analysis: the first stage lacks power, and, hence, the second stage may be biased. We, therefore, focus on the results from the OLS and reduced form specifications. Table A6 in the online appendix presents the results of all specifications, including 2SLS for completeness. The results of OLS and reduced form specifications are largely robust to the inclusion of 30 province-specific time trends. In the OLS, the coefficient on Local is statistically significant for the social expenditure share, construction output, and extra-budgetary revenue, but is imprecisely estimated for the number of teachers per capita. In the reduced form specification, all results are statistically significant. Thus, overall, the patterns of the effect of Local are similar to the baseline, albeit not always significant.
} 
where the promoted party secretary is local to outcomes in provinces where the promoted party secretary is an outsider, before the promotion occurs. As the appointment of a local party secretary may be endogenous, we exploit the idea behind our instrument that a new general secretary can replace each incumbent party secretary at the expiration of his five-year term. We regress each of the four policy outcomes on interactions between whether the new general secretary has ever served in province $p$ and the number of years until the incumbent party secretary's five-year term expires. In particular, for each general secretary switch, we identify the incumbent party secretary, and the number of years until his five-year term expires (that is, the number of years for which $T_{p t}=1$ ). To distinguish between the different years in this transition period, we create indicator variables for "one year until expiration," "two years until expiration," and so on. We denote these dummies $D[-1]_{p t}, D[-2]_{p t}$, etc.; they are labeled to reflect the years left to the expiration of the incumbent party secretary's term. We also create indicator variables for each of the first five years after the expiration of the incumbent party secretary's term (i.e., after the transition period, when $T=0$ ). These are denoted by $D[1]_{p t}, D[2]_{p t}$, etc. In other words, we create a timeline relative to the expiration of the five-year term of the incumbent party secretary. ${ }^{25}$ We then regress of each of the four outcomes on $G s W o r k_{p t}$, indicator variables for each year on the timeline, and interactions between GsWork $_{p t}$ and each timeline dummy. Figure A5 on the online appendix presents the coefficients on the interaction terms, along with their confidence intervals, relative to the level two years before the expiration of the incumbent party secretary's term. These coefficients capture the change that occurs, in provinces where the general secretary worked, around the expiration of the incumbent's five-year term.

For three of the four outcomes - social expenditure share, teachers, and construction output - we see no visible effects for the years before the expiration of the incumbent party secretary's term. While the coefficients are imprecisely estimated, the fact that they are very close to zero suggests that there are no pre-trends in these three outcomes. When it comes to EBR, however, the effect in the last year of the incumbent party secretary's term is negative,

\footnotetext{
${ }^{25}$ Because the switches in 1987 and in 1990 lie only three years apart, the timelines relative to the expiration of the party secretary who is an incumbent in 1987 and 1990, respectively, may overlap. This occurs whenever the relevant incumbent party secretary is different in 1987 and in 1990. In these cases, we assign province-year observations during Ziyang's tenure $(1987,1988,1989)$ to the timeline relative to the expiration of the party secretary who is the incumbent when Ziyang assumes the general secretary position.
} 
which cautions that there may be a pre-trend in EBR. Note, however, that the effect in the last year before the incumbent's term expiration is small relative to the drop in EBR after the expiration of the term: EBR continues to fall until the fourth year of the subsequent term, and the magnitude of this drop is substantially larger after compared to before the expiration of the incumbent's term.

\section{Policy outcomes and the central promotion mechanism}

Having established the systematic policy differences between local and outsider party secretaries, we turn to the analysis of the sources of these differences. In this section, we examine how the policy outcomes, in which locals and outsiders differ, are rewarded (or punished) by the center's promotion mechanism. Chen et al. (2005) and Li and Zhou (2005) have demonstrated that, consistent with proclaimed objectives, the probability of promotion of a party secretary or governor is strongly tied to provincial economic growth. Our question here is how the overall focus on provincial growth translates into career concerns for actual policies. Thus, we use empirical methodology of Li and Zhou (2005) and replicate their analysis, adding our main policy outcomes as potential determinants of promotion. ${ }^{26}$ In particular, we estimate ordered Probit regressions in which the dependent variable $y_{p t}$ takes one of the following three values: 0 , if the the provincial leader was demoted in year $t+1$ in province $p ; 1$, if he remained in the same-level position in year $t+1$; and 2 , if he was promoted. We focus on the effect of our policy variables, and take their value at year $t$ to be the average of the respective policy outcome over the leader's tenure up to, and including, time period t. We control for all potential determinants of promotion considered in Li and Zhou (2005), which we discussed in Section 4, including province and year fixed effects. Following Li and Zhou (2005), we include all top provincial leaders, namely, party secretaries and governors, in the sample.

Columns (1)-(4) of Table 5 report the results. The two panels of the table report results with and without an additional control for provincial economic growth over the leader's tenure (which is the main focus of the career incentive scheme). We find the center's pro-

\footnotetext{
${ }^{26}$ See Section 3 of Li and Zhou (2005) for details on the exact specification.
} 
motion mechanism rewards infrastructure investments, whereas social spending or the provision of public goods such as education are not significantly associated with promotions. In particular, irrespective of whether we control for economic growth, promotions are positively and significantly related to construction output, and unrelated to social spending or teachers per capita. Thus, provincial officials face strong incentives to promote short-run growth-enhancing investments in physical infrastructure, while investments into education and health care are not rewarded. Below we discuss that a possible reason for why the center rewards the provision of construction over education is that construction faster translates into economic growth, which is consistent with promotion based on the province's economic performance over the secretary's term. ${ }^{27}$

Column (4) presents the results for EBR. Despite the official rhetoric about EBR being an instrument for local corruption, described above, boosting EBR is positively associated with career concerns. A potential explanation for this is that EBR gives provincial leaders unofficial means to influence their career, for example by using EBR as bribes in exchange for promotions or reversals of potential demotions.

In sum, the center's promotion mechanism gives provincial officials strong career incentives to invest in construction infrastructure and raise EBR, but it does not reward social spending and public goods provision. If we restrict the sample to party secretaries only, the results are similar, but less precisely estimated due to the considerable reduction in the sample size, which leads to a (marginal) loss of statistical significance for construction output. However, as the point estimates remain very similar in magnitude, it is reasonable to conclude that all top provincial officials face the same career incentives regarding the choice between spending on social public goods vs. infrastructure.

These results, together with those presented in the previous section, suggest that outsiders are more likely to adhere to this career-maximizing policy mix than local party secretaries. In particular, as shown in Section 5, outsiders spend more on construction and raise more

\footnotetext{
${ }^{27}$ The lack of rewards for social spending does not mean that the center was unconcerned about social stability. All provincial leaders were required to maintain social stability (Edin, 2003), and the significant rise in social unrest in the middle of the 2000s was associated with an official change in center's proclaimed priorities from economic growth to a so-called "harmonious society" under Hu Jintao's rule, which emphasized the costs of growth in terms of environmental problems, inequality, and instability (People's Daily, 2004; Wong, 2005). All the results in the paper go through when we exclude the years after the proclaimed change in the center's goals, i.e., 2004 and 2005.
} 
EBR, while locals spend more on education and health care. Therefore, outsiders should also have more lucrative career advancements than locals. The last column of Table 5 reports the results of the estimation of the promotion mechanism with Local as the main explanatory variable. As expected, we find that being local has significant negative effect on the future career advancement of provincial leaders. Irrespective of the set of covariates, the coefficient on local is always negative and statistically significant. If we consider the sample of party secretaries only, the coefficient on local remains negative (and statistically significant).

These results suggest that we can think of outsiders as career-maximizers, whereas locals may either be partly driven by other considerations, or may be constrained in implementing the career-maximizing policy mix.

\section{Exploring the mechanism}

Having established that local and outsider party secretaries chose different policies and that these differences result in tangible costs in terms of career advancement for the locals, we now explore potential mechanisms driving these results.

\subsection{Differences in knowledge or experience}

The observed policy differences between locals and outsiders may be due to differences in the set of attainable policies. In particular, party secretaries with a particular background can be more or less efficient in raising funds, producing public goods, or making productive infrastructure investments. In particular, the differences in policy outcomes such as construction output or the size of EBR, which are rewarded by the promotion mechanism, could potentially be driven by information or skill constraints. Locals, due to their background, are less likely to have served in high positions in the center than outsiders; these differences in experience may result in differences in skills and knowledge. Importantly, the differences in the shares of budgetary spending cannot be explained by differences in skills and knowledge, however, because the allocation of budgetary expenditure is at the party secretary's discretion and, hence, the career-maximizing allocation can be replicated by any party secretary. At the same time, local party secretaries may have better knowledge of local conditions, because 
locals spent more time in the province before assuming the position as party secretary. If either experience necessary for the top-level job, or local knowledge, are important driving forces behind the differences in locals' and outsiders' policies, then we would expect the policy differences between locals and outsiders to decrease (and eventually disappear) with tenure on the job, as local party secretaries get experience on the top-level position and outsider party secretaries acquire knowledge about the province while governing it.

Table A7 in the online appendix presents the results of regressions where, in addition to our standard sets of explanatory variables, we include an interaction term between the Local dummy and tenure (from which we subtract the sample mean before generating the cross-term). As in the baseline specification, we include the full set of controls as well as economic-region-specific time trends, and employ two-way clustering. ${ }^{28}$ In all OLS regressions (Panel A), the coefficients on the interaction terms are precisely-estimated zeros. In the IV specifications (Panel B), the sign of the coefficients on the interaction term coincide with the sign of the coefficient on Local in all cases. Thus, tenure on the job does not significantly affect the differences between locals' and outsiders' policies, and if anything, the differences increase rather than decrease over time (although, this effect is imprecisely estimated). This is the opposite of what one would expect if differences in skills and knowledge, acquired during the work experience, had driven the differences between locals' and outsiders' policy choices.

\subsection{Attachment to the local population or local elites}

An alternative mechanism is that policy differences between local and outsider party secretaries are caused by differences in their objectives. In particular, party secretaries may develop attachment to the province in which they make significant career advancements. For local party secretaries, this is the province that they govern.

Attachment to the province may take the form of an innate preference towards the people in the province, which could have developed as local party secretaries and their families lived and worked in the province. Alternatively, it may originate in social ties to local elites, who

\footnotetext{
${ }^{28}$ In the IV regressions, in addition to Local, instrumented with the instrument $Z$, we use $(Z \times$ Tenure $)$ as an instrument for $($ Local $\times$ Tenure $)$.
} 
helped the local party secretaries advance their careers long before they rose to the position of party secretary.

Both innate preferences towards the province and elite influence would result in the local party secretaries' career concerns being partly compromised by other objectives - of the local population, or of the local elites, respectively. As we do not observe preferences directly, it is impossible to definitively reject either of the two mechanisms. Moreover, they are not mutually exclusive. Below we provide evidence that helps to party discriminate between these two mechanisms, as it is more easily reconcilable with social ties to local low-level elites being the main mechanism at play.

The timing of formation of the home bias First, we examine at which point in party secretaries' lives the home bias towards the province is formed. We compare the policy choices of party secretaries who made their career in the province (local party secretaries) with policy choices of party secretaries who were born or studied in the province, i.e., native party secretaries. Potentially, attachment to a particular place can be formed during youth and adolescence, and the attachment to the native province may be at least as strong as to provinces where political leaders worked as adults.

Since a native province dummy is included in all regressions with individual controls, we can compare the effects of being local to being native. Table 4 displays the results for all four policy outcomes. The evidence sharply contrasts with a conjecture of similar effects for local and native party secretaries. For all outcomes in the IV regressions, and for three out of four outcomes in the OLS regressions, the coefficients on the native and the local dummies have the opposite sign. Thus, we can conclude that the home bias of local party secretaries, which is our main focus, is developed during their professional careers, despite the fact that there are more native party secretaries among locals than among outsiders. The home bias developed during the professional career may, however, reflect both innate preference and social ties.

Interactions with measures of provincial inequality Higher spending on education and health care is consistent with locals' affinity towards the local population: such public goods were severely under-provided in China during the time period that we analyze (Whit- 
ing, 1996; Luo et al., 2010). ${ }^{29}$ If our results are driven by local party secretaries catering to local elites, however, a first-order question is why local elites would care about public goods provision. Elites by definition have little in common with the masses. The Chinese context is not an exception: high-level provincial elites often have access to better schools and hospitals than the population at large and may even send their families and children abroad. What distinguishes local from outsider party secretaries, however, is their relationship to the elites at the lower levels of the Chinese administrative hierarchy, who helped the party secretaries rise through the lower administrative ranks. In contrast to top-level elites, the lower-level elites may, to some extent, value the provision of public services or have extended families who does; this would bring their preferences slightly closer to those of the population.

How close the preferences for public goods provision of the low-level provincial elites are to the preferences of the population varies across provinces. If the home bias of local party secretaries is driven by their affinity to lower-level elites, rather than to the population in general, then a larger preference gap between the low-level elites and the population should reduce the home bias in local party secretaries' social spending. If the low-level elites do not at all use public education or health care because, for instance, they have access to private schools and hospitals, then one should not expect local party secretaries to raise social spending to favor these elites; in contrast, if low-level elites at least partly rely on such services, then local party secretaries may chose to provide higher social spending.

We have no direct measure of the preference gap between the low-level elites and the masses; however, urban-rural inequality may be an indirect proxy for this gap. Table 6 presents results from regressions in which we regress social expenditure and teachers per capita on proxies for urban-rural inequality as well as their interactions with the Local dummy (in addition to our standard set of covariates). We use two proxies for urban-rural inequality: the ratio of mean urban to rural living expenditure per capita and the ratio of urban to rural gross provincial product per employee. Our focus is on the interaction between urban-rural inequality and Local. The sign of the estimated coefficients is always negative in the OLS regressions and significant in three out of four specifications. The interaction coefficients are much less precisely estimated in the IV regressions, so that only one coefficient - for the

\footnotetext{
${ }^{29}$ In Section 7.4 below we discuss why the center may rationally design a promotion mechanism that induces career-focused party secretaries to under-invest in education and health care.
} 
teachers per capita - is statistically significant at $10 \%$ level (and one coefficient out of four flips its sign). Albeit these results are not conclusive, they suggest that when intra-provincial inequality is larger, local party secretaries have a lower bias in favor of spending on social public goods. This evidence is consistent with social ties to local (urban) elites rather than to affinity to general (rural) population being the driving force of the home bias of the local party secretaries. With this interpretation, our results presented in Section 5 suggest that, the smaller the gap between the low-level elite and the population, the more beneficial is elite influence to the population. In the model presented in the online appendix, we derive conditions under which social ties between the provincial leader and the local elites either benefit or hurt the local population, in the presence of a promotion mechanism that gives provincial leaders high-powered career concerns. We show that when the preference gap between the elites and the population is not too large-meaning that the local elites' preferences lie between the population's bliss point and the policy mix encouraged by the promotion mechanism-elite influence is beneficial, and can be viewed as an imperfect substitute for democracy. In contrast, when the elites and the masses do not have any common aspects of preferences, elite influence is harmful, as is common in the literature on elite capture (e.g., Bardhan, 2002; Slinko et al., 2005).

Demotion and retirement If the difference between locals' and outsiders' policies result from locals catering to (low-level) local elites rather than from a general affinity towards the province, then another outstanding question is why party secretaries would sacrifice their career advancement in order to sway policies toward local elites. This may, of course, simply reflect that friendship emerged over the course of serving with them. Another potentially important factor is that, as we discuss in Section 2, rising from low to high positions within the province requires explicit support from low-level local elites. This implies that, at some earlier point in time, significant favors were made to the local party secretary by other key provincial stakeholders. ${ }^{30}$ These favors may have be granted in anticipation of reciprocity; if so, locals may be subject to implicit contracts that de facto require paybacks to the provincial

\footnotetext{
${ }^{30}$ In the words of Liu (2010), "in reality, politicians in China climb up their career ladder by coordinating with the interest of industry, as represented by the central industrial ministries and industrial bureaus at the provincial level and below, which have played a powerful role in the policy process."
} 
elites who helped them rise to prominence. It is unclear, however, why local party secretaries would honor any such implicit contracts once they occupy the top provincial position. One potential commitment mechanism relates to the continuation value of the relationship with local elites. In particular, in the case of dismissal of the local party secretary at the end of the term, relationships to the local elite may remain valuable.

To investigate this, we collected information on where party secretaries find jobs after dismissal (available from 1990 and onwards). Between 1990 and 2005, 61 party secretaries were demoted. Table 7 presents the share of demoted party secretaries that remain in the province in a lower-level job after being demoted from the position as party secretary. Among local party secretaries who were demoted since $1990,56 \%$ got a job in the same province, whereas only $44 \%$ of the outsider secretaries remained in the province after demotion. Moreover, these shares of party secretaries who remained in the province after demotion among locals and outsiders diverged over time. If we restrict the sample to party secretaries demoted since 2000, the respective shares are $75 \%$ for locals and $50 \%$ for outsiders. This evidence is consistent with the hypothesis that it is valuable for party secretaries to maintain their pre-existing social ties with provincial elites, as they can be useful in case of dismissal.

\subsection{Alternative explanation: general secretary's work experience}

The analysis presented above is based on the assumption that the general secretary's work experience in the province affects outcomes only through its effect on the probability of having a local party secretary. This is a strong assumption. In reality, general secretary could himself develop an attachment to the province, which could influence the center's treatment of the province or use his knowledge about the province to make more informed appointment decisions. Above we provided evidence that the center does not seem to favor provinces where the general secretary worked previously in its allocation of favorable fiscal revenue-sharing rules pre-1994, of intergovernmental transfers post-1994, or of Politburo seats to provincial party secretaries (see Table 3 ). The general secretary could potentially also favor local party secretaries by applying more lenient criteria towards them in evaluations for reappointment and promotion which could explain their deviation from the career-maximizing path. This, however, is inconsistent with the presented evidence that locals are punished by 
the promotion mechanism for their home bias (see Table 5).

Another closely related possible interpretation of our results presented in Section 5 is that locals face a different promotion mechanism than outsiders because they may have personal ties to the general secretary. One can imagine, for example, that the general secretary wants to improve both infrastructure and public goods, but that the quality of infrastructure is easier to monitor. Thus, provincial leaders, who do not know the general secretary, would spend on infrastructure to get promoted, while those whom he trusts can invest in public goods. To investigate potential differences in career concerns, we add to specifications reported in columns (1)-(4) of Table 5 the interactions between local and each policy outcome. The results are reported in Table A8 in the online appendix. Panels A and B, respectively, present results of specifications with and without an additional control for provincial economic growth over the leader's tenure. The coefficients on the direct effects show that the center's promotion mechanism for outsiders rewards infrastructure investments, whereas social spending or the provision of public goods such as education are not significantly associated with promotions. Furthermore, the direct effect of EBR is insignificant, which is more congruent with the official rhetoric denouncing EBR. The interaction terms of the policy outcomes with Local $_{p t}$ are never statistically significant suggesting that there are no significant differences in the strength of career incentives between locals and outsiders. Moreover, for three out of four outcomes, the coefficient on the interaction term has the same sign as the main effect; therefore, there is no evidence that locals face weaker incentives than outsiders. Finally, the magnitude of the (insignificant) effect of the interaction term is small relative to the main effect $(1 / 6$ in the case of construction, which is the policy outcome that the center significantly incentivizes).

These results suggest the policy differences that we document in Section 5 are not driven by differences in career concerns of local and outsider party secretaries. We find that both locals and outsiders face strong incentives to prioritize short-run growth-enhancing investments, i.e., construction, over spending on education and health care, but respond differently to these incentives. ${ }^{31}$

\footnotetext{
${ }^{31}$ It is also possible that the general secretary is better able to monitor party secretaries, or pick provincial leaders who are a better match for the province, in provinces where he previously worked. It is not clear, however, why this would lead to a systematic difference in the shares allocated to social spending and construction, as the allocation of spending is both easily observable and at the full discretion of the provincial leadership. Table A9 in the online appendix presents the results of regressions, in which we relate our baseline
} 


\subsection{Understanding the incentives of the center}

Regardless of the mechanism driving the results, from the perspective of the population, having a local party secretary is not harmful. Why would the center halter career advancement of local party secretaries, who spend more on education and health care?

There are two complementary rational explanations. First, the center may not reward social spending because the short-term nature of the evaluation of party secretaries, necessary for provision of strong career incentives, constrains the set of policies that can be incentivized through the promotion mechanism. In choosing the career-maximizing policy mix, the center solves a constrained optimization problem: The provision of high-powered career incentives entails frequent re-evaluation, and hence, short (five-year) terms. This makes it impractical to reward a party secretary based on investments that translate into growth only in the longer run, such as investments into health care and education. Instead, a growth-rewarding promotion mechanism must reward investments that translate into growth over the short time horizon before the party secretary is re-evaluated, such as investments into construction. We illustrate this point in the model presented in the online appendix.

Second, the fact that frequent re-evaluation and rotation is practiced even though it constrains the set of policies that can be induced through the career mechanism suggest that the center perceives important benefits from rotation; potentially because the center perceives important costs from having too strong ties between the party secretary and the province that he governs. Since we do not observe all aspects of governance, there may be other, unobservable aspects of local party secretaries' actions that are undesirable to the center. Our leading interpretation of the mechanism driving the policy divergence between

policy outcomes to the general secretary's work experience on the subsample of province-year observations with outsider party secretaries at the head of the provinces. In all other respects, the specification is similar to Panel A of table 4. If the direct effect of the general secretary's work experience is a valid explanation for our results, one should expect the effect of this variable to be similar to the effect of Local in our baseline results. We find that the sign of the coefficients on the general secretary's work experience for two out of four outcomes, namely, social expenditure share and EBR, is the opposite to the direction of the home bias of local party secretaries. The effect of the general secretary's work experience for construction output is similar in magnitude to the effect of local but, in contrast to the latter, is statistically insignificant. The effect on teachers per capita, however, is significant and has the same sign as the effect of local party secretaries. This evidence suggests that for three out of four outcomes, the alternative explanation that our results are driven by the direct effect of the general secretary's work experience in the province is not valid, as, in contrast to the findings presented in Table A9 in the online appendix, Local has strong and robust effect on these outcomes. As for teachers per capita, the results should be interpreted with caution as they could be driven by the alternative explanation. 
locals and outsiders - that local party secretaries cater to the local elites - suggests that appointing a local party secretary moves political power towards provincial interests. A local party secretary's increased allegiance with provincial interests, in turn, may come at the expense of his loyalty to the center. A fear of weakened loyalty to the center is an additional justification for rotating party officials (Edin, 2003). Such increased provincial allegiance, for instance, may hamper the center's ability to stall social unrest, as provincial leaders with local ties may take the side of the protesters in case of a riot.

\section{Conclusion}

The powerful career concerns faced by high-level officials in China are considered one of the key reasons for the country's stellar economic performance over the last 30 years. One key aspect of this system is frequent re-evaluation and inter-provincial rotation of the top provincial officials, the party secretaries. This practice suggests that the presence of close ties between a party secretary and the province that he governs is undesirable to the center, and, more generally, that there are limits to the power of career incentives in autocracies.

This paper analyzes whether and why party secretaries' local ties affect governance decisions in China. To do this, we exploit an institutional feature of the internal labor market within the Chinese Communist Party to distinguish between "local" party secretaries, who rose from low to high hierarchical levels within the province they govern, and "outsiders," who rose to prominence elsewhere. Despite strong career incentives, the party secretaries' career backgrounds play an important role in their governance decisions. Relative to outsiders, local party secretaries shift resources from construction towards much-needed public goods such as education and health care, and extract less extra-budgetary revenue. As the promotion mechanism rewards investments in infrastructure and construction, but not investments in education and health care, local party secretaries' policy choices come at a considerable career cost, captured by a decreased likelihood of promotion at the end of the term. We also explore the potential mechanisms that could explain local party secretaries' deviation from the career-maximizing policies. While not conclusive, several pieces of evidence suggest that local party secretaries cater to low-level provincial elites, who helped them rise to power. 


\section{References}

Bardhan, Pranab, "Decentralization of Governance and Development," Journal of Economic Perspectives, 2002, 16 (4), 185-205.

Bird, Richard M. and Christine Wong, "China's Fiscal System: A Work in Progress," 2005. Rotman School of Management Working Paper No. 07-11.

Blanchard, Olivier and Andrei Shleifer, "Federalism With and Without Political Centralization: China versus Russia," in "IMF Staff Paper: Transition Economies: How Much Progress?" 2001.

Bo, Zhiyue, "The Institutionalization of Elite Management in China," in Barry J. Naughton and Dali L. Yang, eds., Holding China Together, Cambridge University Press, Cambridge, 2004.

Cameron, Colin A., Jonah B. Gelbach, and Douglas L. Miller, "Bootstrap-Based Improvements for Inference with Clustered Errors," Review of Economics and Statistics, 2008, 90 (3), 414-427.

Chen, Ye, Hongbin Li, and Li-An Zhou, "Relative performance evaluation and the turnover of provincial leaders in China," Economics Letters, 2005, 88 (3), 421-425.

Cole, Matthew, Robert Elliott, and Jing Zhang, "Corruption, Governance and FDI Location in China : A Province-Level Analysis," Discussion Papers 08-06, Department of Economics, University of Birmingham October 2008.

Edin, Maria, "State Capacity and Local Agent Control in China: CCP Cadre Management from a Township Perspective," The China Quarterly, 2003, 173, 35-52.

Enikolopov, Ruben and Ekaterina Zhuravskaya, "Decentralization and political institutions," Journal of Public Economics, December 2007, 91 (11-12), 2261-2290.

Huang, Y., Inflation and Investment Controls in China: The Political Economy of Central-Local Relations during the Reform Era, Cambridge University Press, 1999.

Jia, Ruixie, "Pollution for Promotion," 2014. mimeo.

_ , Masayuki Kudamatsu, and David Seim, "Political Selection in China: Complementary Roles of Connections and Performance," 2014. mimeo.

Jin, Hehui, Yingyi Qian, and Barry R. Weingast, "Regional decentralization and fiscal incentives: Federalism, Chinese style," Journal of Public Economics, September 2005, 89 (9-10), 1719-1742.

Keidel, Albert, "CHINESE REGIONAL INEQUALITIES IN INCOME AND WELL-BEING," Review of Income and Wealth, 2009, 55, 538-561.

Li, Hongbin and Li-An Zhou, "Political turnover and economic performance: the incentive role of personnel control in China," Journal of Public Economics, 2005, 89 (9-10), 1743-1762.

Liu, Derek Taiwei, "Central Control vs. Decentralization in Authoritarian Systems: Career Incentives and Public Goods Provision in China," 2010. SSRN Working Paper No 1642892.

Luo, Renfu, Linxiu Zhang, Jikun Huang, and Scott Rozelle, "Village Elections, Public Goods Investments and Pork Barrel Politics, Chinese-style," The Journal of Development Studies, 2010, $46(4), 662-684$.

Ma, Haitao, Li Yan, Shi Gang, and Xu Huandong, Shouzhi Liang Tiao Xian Guanli Zhidu [Decoupling-Revenue-and-Expenditure Management System], Beijing: China Finance and Economy Press, 2003.

Markevich, Andrei and Ekaterina Zhuravskaya, "M-form Hierarchy with Poorly-diversified Divisions: A case of Khrushchev's Reform in Soviet Russia," Journal of Public Economics, 2011, 95 (11), 1550-1560.

Martinez-Bravo, Monica, Gerard Padro i Miquel, Nancy Qian, and Yang Yao, "Do Local Elections in Non-Democracies Increase Accountability? Evidence from Rural China," NBER Working Papers 16948, National Bureau of Economic Research, Inc April 2011.

$\ldots, \ldots, \ldots$, and _ , "The Effects of Demiocratization on Pubic Goods and redistribution: Evidence from China," 2012. mimeo, Yale University.

Maskin, Eric, Yingyi Qian, and Chenggang Xu, "Incentives, Information, and Organizational 
Form," Review of Economic Studies, April 2000, 67 (2), 359-78.

Montinola, Gabriella, Yingyi Qian, and Barry R. Weingast, "Federalism, Chinese Style: The Political Basis for Economic Success in China," World Politics, 1995, 48, 50-81.

Oi, Jean C., "Fiscal Reform and the Economic Foundations of Local State Corporatism in China," World Politics, October 1992, 45 (1), 99-126.

People's Daily, "China Says Goodbye to Blind Pursuit of GDP Growth," People's Daily, 2004.

Riker, William H., Federalism: Origins, Operation, Significance, Boston, MA: Little, Brown and Co., 1964.

Shih, Victor C., Factions and Finance in China: Elite Conflict and Inflation, Cambridge: Cambridge University Press, 2007.

Slinko, Irina, Evgeny Yakovlev, and Ekaterina Zhuravskaya, "Laws for Sale: Evidence from Russian Regions," American Law and Economics Review, 2005, 7 (1), 284-318.

Tsai, Lily L., Accountability Without Democracy: Solidary Groups and Public Goods Provision in Rural China Cambridge Studies in Comparative Politics, Cambridge University Press, 2007.

_ , "Solidary Groups, Informal Accountability, and Local Public Goods Provision in Rural China," The American Political Science Review, 2007, 101 (2), pp. 355-372.

Whiting, Susan, "Contract Incentives and Market Discipline in China's Rural Industrial Sector," in John McMillan and Barry Naughton, eds., Reforming Asian Socialism, The Growth of Market Institutions, Ann Arbor, University of Michigan Press, 1996, pp. 66-110.

Wong, Christine, "Can China Change Development Paradigm for the 21st century Đ Fiscal Policy Options for Hu Jintao and Wen Jiabao after Two Decades of Muddling through," 2005. Stiftung Wissenschaft und Politik, Working Paper FG 7, SWP Berlin.

World Bank, "China National Development and Sub-National Finance: A Review of Provincial Expenditures," Technical Report 22951-CHA., World Bank Poverty Reduction and Economic Management Unit, East Asia and Pacific Region 2002.

Zhan, Jing Vivian, "Why Does Local Finance Go Extra-budgetary? Analysis of Informal Fiscal Practices in China," 2009. 
Table 1: Party secretary backgrounds

\begin{tabular}{lccc}
\hline Description & Overall & Local & Not local \\
\hline Local = worked both in high and low positions in prov. & $35 \%$ & $100 \%$ & $0 \%$ \\
Worked in center & $56 \%$ & $41 \%$ & $63 \%$ \\
Worked in center in high positions & $27 \%$ & $11 \%$ & $35 \%$ \\
Worked in other provinces & $72 \%$ & $37 \%$ & $91 \%$ \\
Worked in other prov. in high positions & $49 \%$ & $14 \%$ & $68 \%$ \\
Worked elsewhere in high positions & $64 \%$ & $22 \%$ & $87 \%$ \\
Did not work in this province & $41 \%$ & $0 \%$ & $62 \%$ \\
Did not work in this prov. in high positions & $43 \%$ & $0 \%$ & $66 \%$ \\
Politburo member & $11 \%$ & $14 \%$ & $9 \%$ \\
Native province & $12 \%$ & $25 \%$ & $4 \%$ \\
Has higher education & $66 \%$ & $59 \%$ & $70 \%$ \\
Length of time on the job as party secretary & 4.2 years & 4.6 years & 4.0 years \\
\hline
\end{tabular}


Table 2: First stage

\begin{tabular}{|c|c|c|c|c|}
\hline & \multicolumn{4}{|c|}{ Dependent variable: Party Secretary is Local } \\
\hline & $(1)$ & $(2)$ & $(3)$ & $(4)$ \\
\hline $\begin{array}{l}\text { General Secretary Worked } \times \\
\text { Term Expires }\end{array}$ & $\begin{array}{l}0.339^{* *} \\
(0.135)\end{array}$ & $\begin{array}{l}0.430^{* * *} \\
(0.136)\end{array}$ & $\begin{array}{l}0.309^{* *} \\
(0.134)\end{array}$ & $\begin{array}{l}0.414^{* * *} \\
(0.116)\end{array}$ \\
\hline Age & & $\begin{array}{c}0.00824 \\
(0.00743)\end{array}$ & & $\begin{array}{l}0.00767 \\
(0.00724)\end{array}$ \\
\hline Tenure & & $\begin{array}{c}0.00491 \\
(0.0131)\end{array}$ & & $\begin{array}{c}0.00346 \\
(0.0140)\end{array}$ \\
\hline Higher education & & $\begin{array}{r}-0.0155 \\
(0.136)\end{array}$ & & $\begin{array}{c}-0.00577 \\
(0.132)\end{array}$ \\
\hline Native province & & $\begin{array}{l}0.514^{* * *} \\
(0.0723)\end{array}$ & & $\begin{array}{l}0.492^{* * *} \\
(0.0783)\end{array}$ \\
\hline $\begin{array}{l}\text { Last term before } \\
\text { retirement }\end{array}$ & & $\begin{array}{l}-0.0329 \\
(0.0583)\end{array}$ & & $\begin{array}{l}-0.0558 \\
(0.0530)\end{array}$ \\
\hline Serves second term & & $\begin{array}{c}-0.0190 \\
(0.0292)\end{array}$ & & $\begin{array}{r}-0.0178^{*} \\
(0.00946)\end{array}$ \\
\hline Worked in center & & $\begin{array}{l}-0.207^{* * *} \\
(0.0489)\end{array}$ & & $\begin{array}{l}-0.178^{* * *} \\
(0.0496)\end{array}$ \\
\hline Politburo member & & & $\begin{array}{c}-0.000685 \\
(0.138)\end{array}$ & $\begin{array}{l}0.0589 \\
(0.100)\end{array}$ \\
\hline MRR & & & $\begin{array}{l}-0.161 \\
(0.289)\end{array}$ & $\begin{array}{l}-0.104 \\
(0.282)\end{array}$ \\
\hline Log population & & & $\begin{array}{l}0.0856 \\
(0.411)\end{array}$ & $\begin{array}{c}0.170 \\
(0.381)\end{array}$ \\
\hline Log urbanization & & & $\begin{array}{l}-0.190 \\
(0.162)\end{array}$ & $\begin{array}{l}-0.119 \\
(0.124)\end{array}$ \\
\hline 1yr Lagged Log GPP & & & $\begin{array}{l}-0.721^{* *} \\
(0.336)\end{array}$ & $\begin{array}{l}-0.547 \\
(0.365)\end{array}$ \\
\hline $\begin{array}{l}\text { GPP growth of } \\
\text { predecessor }\end{array}$ & & & $\begin{array}{c}1.141 \\
(1.300)\end{array}$ & $\begin{array}{c}1.150 \\
(1.188)\end{array}$ \\
\hline Average GPP growth & & & $\begin{array}{c}1.442 \\
(1.249)\end{array}$ & $\begin{array}{c}1.317 \\
(1.145)\end{array}$ \\
\hline Controls & No & Indiv. & Prov. & All \\
\hline Mean, dept. var & 0.38 & 0.38 & 0.40 & 0.40 \\
\hline Number of observations & 755 & 753 & 709 & 709 \\
\hline Adj. R-Squared & 0.29 & 0.42 & 0.32 & 0.42 \\
\hline F-stat, two-way clusters & 5.35 & 8.47 & 4.45 & 10.47 \\
\hline F-stat, robust & 18.68 & 36.38 & 15.65 & 32.64 \\
\hline
\end{tabular}

Note: Linear probability OLS regressions. The dependent variable takes the value one if the party secretary is local. In addition to the displayed controls, all models include province and year fixed effects, and six economic region-specific time trends. Standard errors are adjusted for two-way non-nested clusters, with the first dimension of clusters being province and the second dimension of clusters being the general secretary's career background during each party congress spell. We report the F-statistics on the excluded instrument from the model with two-way clusters, as well as the F-statistic from a model with robust standard errors.

$* \mathrm{p}<0.10,{ }^{* *} \mathrm{p}<0.05, * * * \mathrm{p}<0.01$. 
Table 3: Reality check on excludability of the instrument

\begin{tabular}{|c|c|c|c|c|c|c|}
\hline \multicolumn{7}{|l|}{ Panel A } \\
\hline \multirow[t]{2}{*}{ Dependent variable: } & \multicolumn{2}{|c|}{$\begin{array}{c}\text { Fiscal MRR } \\
\text { (before fiscal reform) }\end{array}$} & \multicolumn{2}{|c|}{$\begin{array}{l}\text { Net fiscal transfer } \\
\text { (after fiscal reform) }\end{array}$} & \multicolumn{2}{|c|}{$\begin{array}{l}\text { PS Politburo Member } \\
\text { (all years) }\end{array}$} \\
\hline & $(1)$ & $(2)$ & $(3)$ & $(4)$ & $(5)$ & (6) \\
\hline GS was born and/or studied in the province & $\begin{array}{c}0.089 \\
(0.135)\end{array}$ & $\begin{array}{c}0.087 \\
(0.090)\end{array}$ & $\begin{array}{l}-0.086 \\
(0.094)\end{array}$ & $\begin{array}{l}-0.051 \\
(0.085)\end{array}$ & $\begin{array}{c}0.103 \\
(0.106)\end{array}$ & $\begin{array}{c}0.016 \\
(0.089)\end{array}$ \\
\hline GS worked in the province & $\begin{array}{c}0.073 \\
(0.049)\end{array}$ & $\begin{array}{c}0.046 \\
(0.030)\end{array}$ & $\begin{array}{c}0.038 \\
(0.040)\end{array}$ & $\begin{array}{l}-0.027 \\
(0.045)\end{array}$ & $\begin{array}{l}-0.043 \\
(0.046)\end{array}$ & $\begin{array}{l}-0.024 \\
(0.032)\end{array}$ \\
\hline PS is Politburo member & & $\begin{array}{r}0.069^{*} \\
(0.037)\end{array}$ & & $\begin{array}{l}-0.048 \\
(0.075)\end{array}$ & & \\
\hline Controls & No & All & No & All & No & All \\
\hline Number of observations & 369 & 367 & 268 & 259 & 755 & 709 \\
\hline Adj. R-Squared & 0.82 & 0.87 & 0.96 & 0.96 & 0.35 & 0.42 \\
\hline \multicolumn{7}{|l|}{ Panel B } \\
\hline \multirow[t]{2}{*}{ Dependent variable: } & \multicolumn{2}{|c|}{$\begin{array}{c}\text { Fiscal MRR } \\
\text { (before fiscal reform) }\end{array}$} & \multicolumn{2}{|c|}{$\begin{array}{l}\text { Net fiscal transfer } \\
\text { (after fiscal reform) }\end{array}$} & \multicolumn{2}{|c|}{$\begin{array}{l}\text { PS Politburo Member } \\
\text { (all years) }\end{array}$} \\
\hline & (1) & $(2)$ & $(3)$ & $(4)$ & $(5)$ & (6) \\
\hline GS was born and/or studied in the province & $\begin{array}{c}0.112 \\
(0.161)\end{array}$ & $\begin{array}{l}0.097 \\
(0.101)\end{array}$ & $\begin{array}{l}-0.074 \\
(0.105)\end{array}$ & $\begin{array}{l}-0.027 \\
(0.080)\end{array}$ & $\begin{array}{c}0.039 \\
(0.098)\end{array}$ & $\begin{array}{l}-0.033 \\
(0.103)\end{array}$ \\
\hline GS Worked $\times$ Term Expires & $\begin{array}{c}0.025 \\
(0.050)\end{array}$ & $\begin{array}{c}0.025 \\
(0.047)\end{array}$ & $\begin{array}{c}0.015 \\
(0.047)\end{array}$ & $\begin{array}{c}-0.073 \\
(0.046)\end{array}$ & $\begin{array}{c}0.097 \\
(0.106)\end{array}$ & $\begin{array}{c}0.095 \\
(0.091)\end{array}$ \\
\hline PS is Politburo member & & $\begin{array}{c}0.067^{*} \\
(0.035)\end{array}$ & & $\begin{array}{l}-0.054 \\
(0.075)\end{array}$ & & \\
\hline Controls & No & All & No & All & No & All \\
\hline Number of observations & 369 & 367 & 268 & 259 & 755 & 709 \\
\hline Adj. R-Squared & 0.82 & 0.86 & 0.96 & 0.97 & 0.35 & 0.43 \\
\hline
\end{tabular}


Table 4: The impact of Local on provincial governance

\begin{tabular}{|c|c|c|c|c|}
\hline \multirow[b]{2}{*}{ Dependent variable: } & \multicolumn{4}{|c|}{ Panel A: OLS } \\
\hline & Social & Teachers & Construction & EBR \\
\hline Party Secretary is Local & $\begin{array}{c}0.00975^{* *} \\
(0.00467)\end{array}$ & $\begin{array}{c}0.0169^{*} \\
(0.00922)\end{array}$ & $\begin{array}{l}-0.0770^{*} \\
(0.0409)\end{array}$ & $\begin{array}{l}-0.0658^{* *} \\
(0.0283)\end{array}$ \\
\hline Tenure & $\begin{array}{l}-0.000765 \\
(0.000771)\end{array}$ & $\begin{array}{c}-0.000385 \\
(0.00241)\end{array}$ & $\begin{array}{l}-0.00504 \\
(0.00827)\end{array}$ & $\begin{array}{r}0.00768^{*} \\
(0.00428)\end{array}$ \\
\hline Native province & $\begin{array}{l}-0.00884^{* *} \\
(0.00364)\end{array}$ & $\begin{array}{l}-0.0306^{* *} \\
(0.0141)\end{array}$ & $\begin{array}{c}0.0300 \\
(0.0356)\end{array}$ & $\begin{array}{r}-0.00702 \\
(0.0299)\end{array}$ \\
\hline Politburo member & $\begin{array}{l}-0.0169 * * * \\
(0.00372)\end{array}$ & $\begin{array}{l}-0.0139 \\
(0.0159)\end{array}$ & $\begin{array}{c}0.102^{* *} \\
(0.0446)\end{array}$ & $\begin{array}{r}-0.00192 \\
(0.0430)\end{array}$ \\
\hline \multirow[t]{2}{*}{ Within R-squared } & $\begin{array}{c}\text { All } \\
0.60\end{array}$ & $\begin{array}{c}\text { All } \\
0.53\end{array}$ & $\begin{array}{c}\text { All } \\
0.96\end{array}$ & $\begin{array}{c}\text { All } \\
0.80\end{array}$ \\
\hline & \multicolumn{4}{|c|}{ Panel B: IV } \\
\hline Dependent variable: & Social & Teachers & Construction & EBR \\
\hline Party Secretary is Local & $\begin{array}{l}0.0351^{* *} \\
(0.0154)\end{array}$ & $\begin{array}{c}0.0898^{*} \\
(0.0477)\end{array}$ & $\begin{array}{l}-0.323^{* * *} \\
(0.120)\end{array}$ & $\begin{array}{l}-0.515^{\text {*** }} \\
(0.168)\end{array}$ \\
\hline Tenure & $\begin{array}{c}-0.000848 \\
(0.000770)\end{array}$ & $\begin{array}{c}-0.000929 \\
(0.00240)\end{array}$ & $\begin{array}{c}-0.00464 \\
(0.00668)\end{array}$ & $\begin{array}{c}0.00982 \\
(0.00682)\end{array}$ \\
\hline Native province & $\begin{array}{c}-0.0205^{* *} \\
(0.00861)\end{array}$ & $\begin{array}{l}-0.0632^{* *} \\
(0.0321)\end{array}$ & $\begin{array}{c}0.141^{* *} \\
(0.0656)\end{array}$ & $\begin{array}{c}0.193^{*} \\
(0.101)\end{array}$ \\
\hline Politburo member & $\begin{array}{l}-0.0193^{* * *} \\
(0.00292)\end{array}$ & $\begin{array}{l}-0.0188 \\
(0.0206)\end{array}$ & $\begin{array}{c}0.117^{* * *} \\
(0.0381)\end{array}$ & $\begin{array}{c}0.0281 \\
(0.0660)\end{array}$ \\
\hline \multirow[t]{2}{*}{ Controls } & All & All & All & All \\
\hline & \multicolumn{4}{|c|}{ Panel C: Reduced form } \\
\hline Dependent variable: & Social & Teachers & Construction & EBR \\
\hline GS Worked $\times$ Term Expires & $\begin{array}{l}0.0155^{* * *} \\
(0.00517)\end{array}$ & $\begin{array}{c}0.0369^{*} \\
(0.0188)\end{array}$ & $\begin{array}{l}-0.134^{* * *} \\
(0.0368)\end{array}$ & $\begin{array}{l}-0.232^{* * *} \\
(0.0372)\end{array}$ \\
\hline Tenure & $\begin{array}{c}-0.000779 \\
(0.000810)\end{array}$ & $\begin{array}{r}-0.000272 \\
(0.00237)\end{array}$ & $\begin{array}{l}-0.00526 \\
(0.00897)\end{array}$ & $\begin{array}{c}0.00705^{*} \\
(0.00370)\end{array}$ \\
\hline Native province & $\begin{array}{l}-0.00275 \\
(0.00430)\end{array}$ & $\begin{array}{l}-0.0188 \\
(0.0143)\end{array}$ & $\begin{array}{l}-0.0198 \\
(0.0259)\end{array}$ & $\begin{array}{l}-0.0661^{* * *} \\
(0.0197)\end{array}$ \\
\hline Politburo member & $\begin{array}{c}-0.0166^{* * *} \\
(0.00492)\end{array}$ & $\begin{array}{l}-0.0134 \\
(0.0150) \\
\end{array}$ & $\begin{array}{l}0.0992^{* *} \\
(0.0500) \\
\end{array}$ & $\begin{array}{r}0.00195 \\
(0.0406) \\
\end{array}$ \\
\hline $\begin{array}{l}\text { Controls } \\
\text { Within R-squared }\end{array}$ & $\begin{array}{c}\text { All } \\
0.60\end{array}$ & $\begin{array}{c}\text { All } \\
0.53\end{array}$ & $\begin{array}{c}\text { All } \\
0.96\end{array}$ & $\begin{array}{c}\text { All } \\
0.82\end{array}$ \\
\hline $\begin{array}{l}\text { Mean, dept. var } \\
\text { Number of observations }\end{array}$ & $\begin{array}{l}0.26 \\
679\end{array}$ & $\begin{array}{c}11.97 \\
690\end{array}$ & $\begin{array}{l}3.61 \\
696\end{array}$ & $\begin{array}{l}3.07 \\
636\end{array}$ \\
\hline
\end{tabular}

Note: Standard errors are adjusted for two-way non-nested clusters, with the first dimension of clusters being province and the second dimension of clusters being the general secretary's career background during each party congress spell. All controls are as in column (4) of Table 2, and include province- and year fixed effects, as well as six economic region-specific time trends. 
Table 5: Promotion mechanism, policy outcomes, and career backgrounds

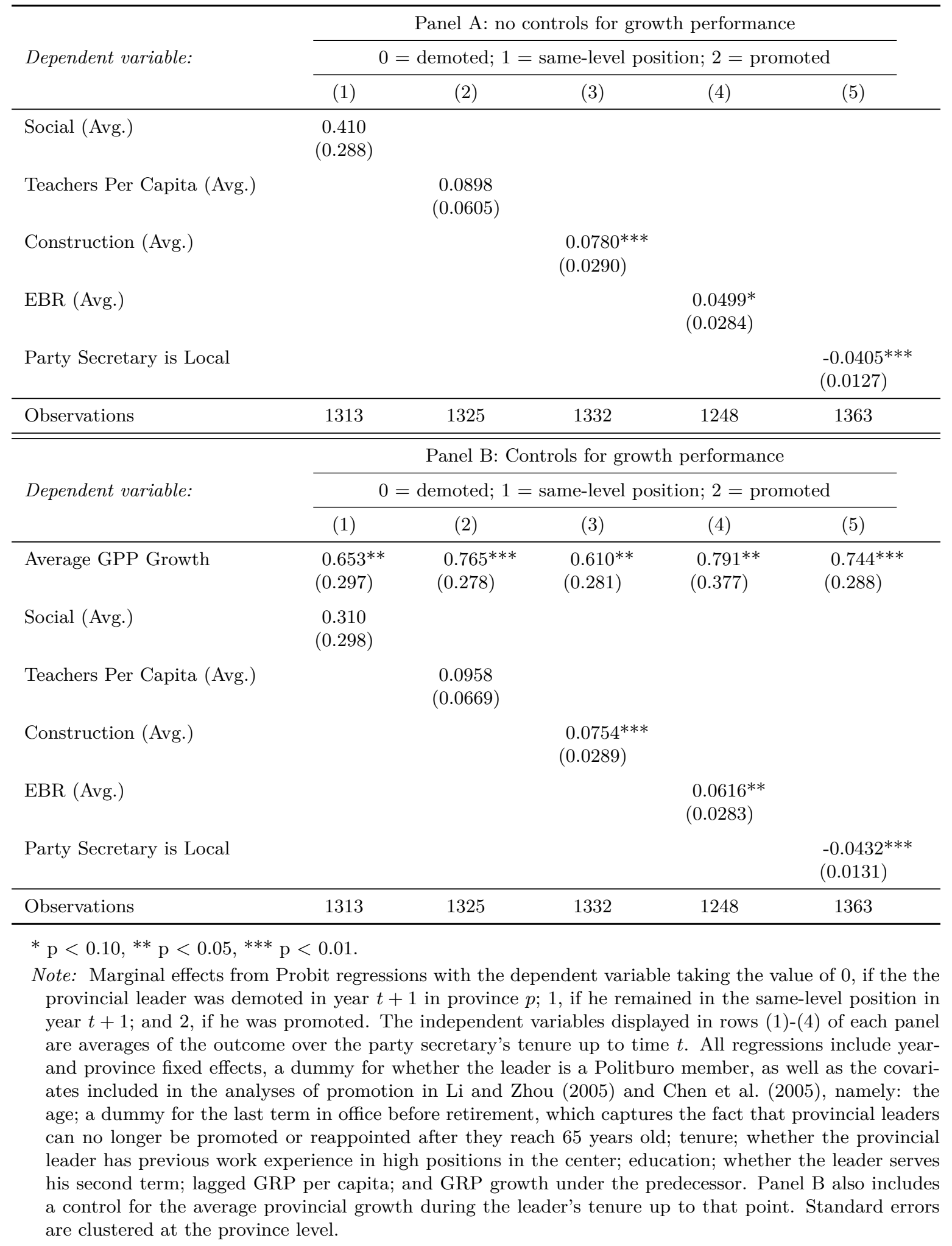


Table 6: Impact of local and measures of intra-province inequality

\begin{tabular}{|c|c|c|c|c|}
\hline \multirow[b]{2}{*}{ Dependent variable: } & \multicolumn{4}{|c|}{ Panel A: OLS } \\
\hline & Social & Teachers & Social & Teachers \\
\hline PS is Local & $\begin{array}{l}0.0403^{* * *} \\
(0.0144)\end{array}$ & $\begin{array}{l}0.105^{* * *} \\
(0.0228)\end{array}$ & $\begin{array}{c}0.0127 \\
(0.0126)\end{array}$ & $\begin{array}{l}0.0792^{* *} \\
(0.0311)\end{array}$ \\
\hline $\begin{array}{l}\text { Urban-rural ratio of } \\
\text { living expenditure per Capita }\end{array}$ & $\begin{array}{l}-0.00669 \\
(0.00455)\end{array}$ & $\begin{array}{r}-0.00772 \\
(0.0172)\end{array}$ & & \\
\hline $\begin{array}{l}\text { Local } \times(\text { UR ratio of } \\
\text { living expenditure per Capita })\end{array}$ & $\begin{array}{l}-0.0122^{* *} \\
(0.00560)\end{array}$ & $\begin{array}{l}-0.0378^{* * *} \\
(0.00939)\end{array}$ & & \\
\hline $\begin{array}{l}\text { Urban-rural ratio of } \\
\text { GRP per employee }\end{array}$ & & & $\begin{array}{l}-0.00201^{* *} \\
(0.000833)\end{array}$ & $\begin{array}{l}0.000894 \\
(0.00284)\end{array}$ \\
\hline $\begin{array}{l}\text { Local } \times(\mathrm{UR} \text { ratio of GRP } \\
\text { per employee })\end{array}$ & & & $\begin{array}{r}-0.000981 \\
(0.00228)\end{array}$ & $\begin{array}{l}-0.0145^{* *} \\
(0.00657)\end{array}$ \\
\hline $\begin{array}{l}\text { Controls } \\
\text { Mean, dept. var } \\
\text { Number of observations }\end{array}$ & $\begin{array}{c}\text { All } \\
0.26 \\
667\end{array}$ & $\begin{array}{c}\text { All } \\
11.99 \\
678\end{array}$ & $\begin{array}{c}\text { All } \\
0.26 \\
670\end{array}$ & $\begin{array}{c}\text { All } \\
11.98 \\
680\end{array}$ \\
\hline Number of observations & \multicolumn{4}{|c|}{ Panel B: IV } \\
\hline Dependent variable: & Social & Teachers & Social & Teachers \\
\hline PS is Local & $\begin{array}{c}0.0385 \\
(0.0399)\end{array}$ & $\begin{array}{c}0.140 \\
(0.165)\end{array}$ & $\begin{array}{c}0.0461 \\
(0.0449)\end{array}$ & $\begin{array}{l}0.348^{* *} \\
(0.156)\end{array}$ \\
\hline $\begin{array}{l}\text { Urban-rural ratio of } \\
\text { living expenditure per Capita }\end{array}$ & $\begin{array}{r}-0.0116^{*} \\
(0.00638)\end{array}$ & $\begin{array}{l}-0.0171 \\
(0.0319)\end{array}$ & & \\
\hline $\begin{array}{l}\text { Local } \times(\text { UR ratio of } \\
\text { living expenditure per Capita })\end{array}$ & $\begin{array}{l}0.00124 \\
(0.0217)\end{array}$ & $\begin{array}{l}-0.0283 \\
(0.0913)\end{array}$ & & \\
\hline $\begin{array}{l}\text { Urban-rural ratio of } \\
\text { GRP per employee }\end{array}$ & & & $\begin{array}{l}-0.00130 \\
(0.00160)\end{array}$ & $\begin{array}{c}0.00918 \\
(0.00604)\end{array}$ \\
\hline $\begin{array}{l}\text { Local } \times(\mathrm{UR} \text { ratio of GRP } \\
\text { per employee })\end{array}$ & & & $\begin{array}{l}-0.00143 \\
(0.00747)\end{array}$ & $\begin{array}{l}-0.0578^{*} \\
(0.0321)\end{array}$ \\
\hline $\begin{array}{l}\text { Controls } \\
\text { Mean, dept. var } \\
\text { Number of observations }\end{array}$ & $\begin{array}{c}\text { All } \\
0.26 \\
667\end{array}$ & $\begin{array}{c}\text { All } \\
11.99 \\
678\end{array}$ & $\begin{array}{c}\text { All } \\
0.26 \\
670\end{array}$ & $\begin{array}{c}\text { All } \\
11.98 \\
680\end{array}$ \\
\hline
\end{tabular}

Note: Standard errors are adjusted for two-way non-nested clusters at province level and General Secretary's career background during each party congress level. All models includes the set of controls displayed in Column 4 of Table 2, as well as province- and year FE and six economic region-specific time trends.

Table 7: Relationship continuation value

\begin{tabular}{lcccc}
\hline & \multicolumn{4}{c}{ \% of demoted PS who found a job in the province } \\
& Since 1990 & Since 1995 & Since 1998 & Since 2000 \\
\hline Local party secretary & $56 \%$ & $59 \%$ & $62 \%$ & $75 \%$ \\
Outsider party secretary & $44 \%$ & $48 \%$ & $53 \%$ & $50 \%$ \\
\hline Number of demoted PS & 61 & 40 & 32 & 24 \\
\hline
\end{tabular}




\section{ONLINE APPENDIX}

\section{A Supplemental figures and tables}

Figure A1: China's government structure

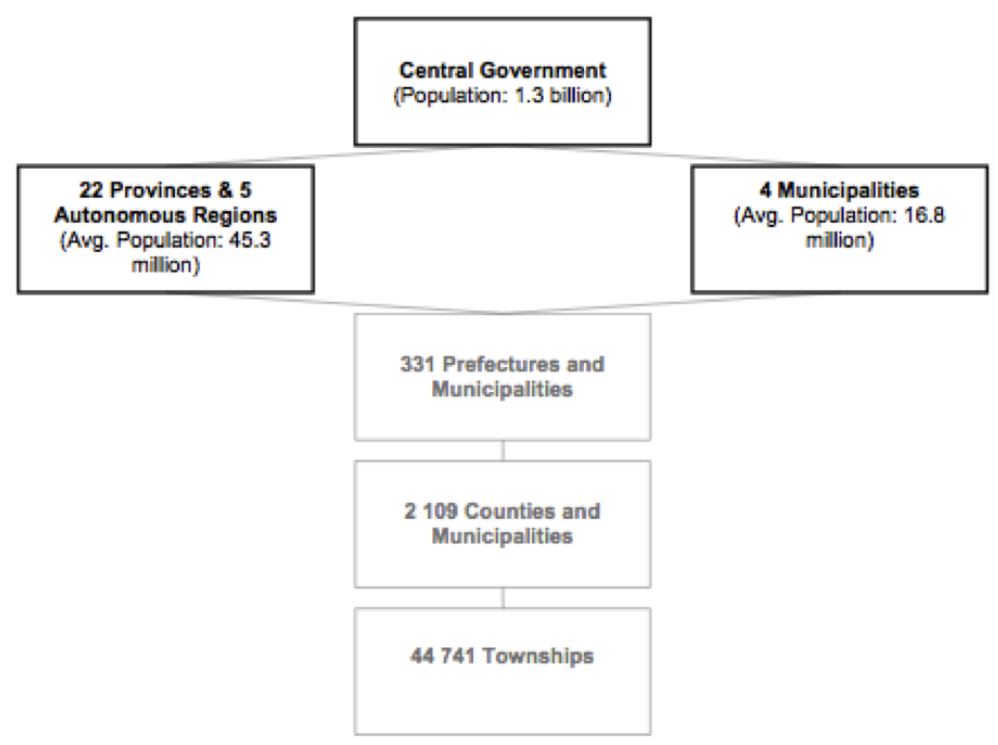

Note: The figure illustrates China's administrative structure in 2003. We focus on the central-provincial level, that is, the two top administrative levels, which are bold in the figure.

Source: Wong (2005). 
Figure A2: Extra-budgetary revenue and anti-corruption measures
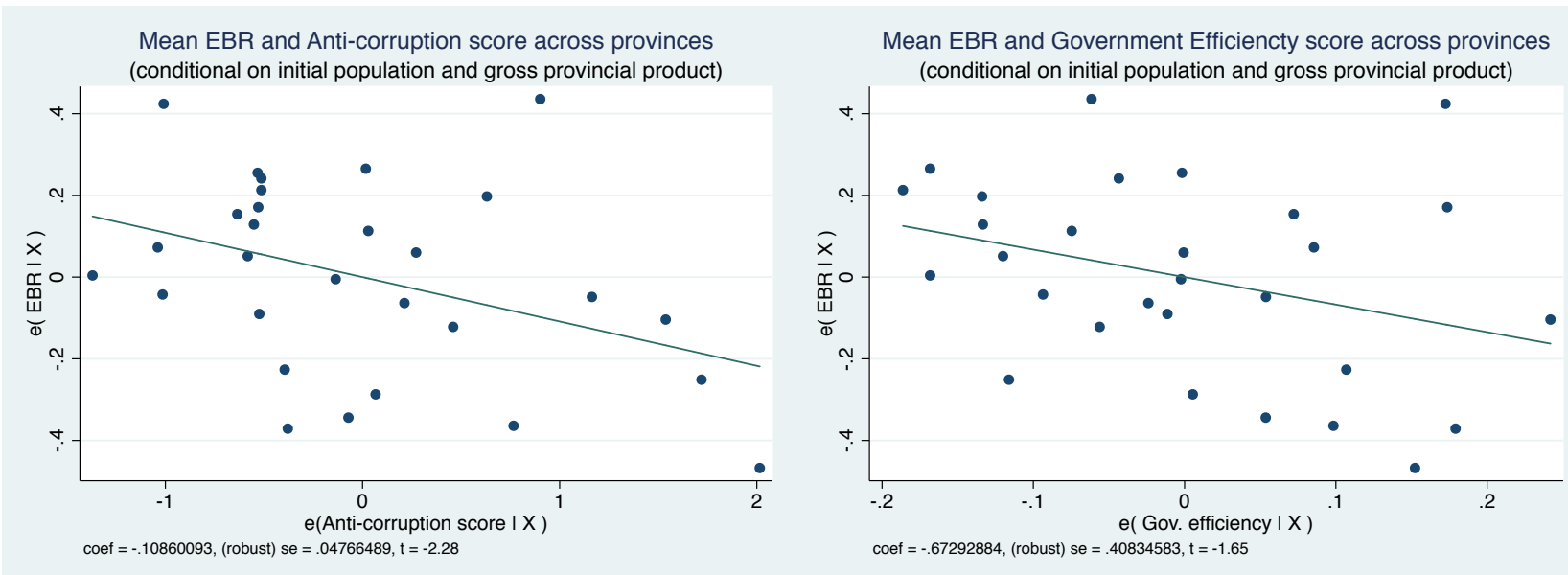

Source: The province-level anti-corruption and efficiency of government scores are obtained from Cole et al. (2008) for the years 1998 - 2003.

Note: Regression results are presented in Columns 1 and 3 of Table A2 in the online appendix. The dependent variable in all regressions is average (log of) extra-budgetary revenue for the years 1998-2003. For the two scores, we use averages for the years 1998 2003 (intra-province variation is small); other controls are taken for the year 1997. 
Figure A3: China's six economic regions (excluding Tibet) and their development paths

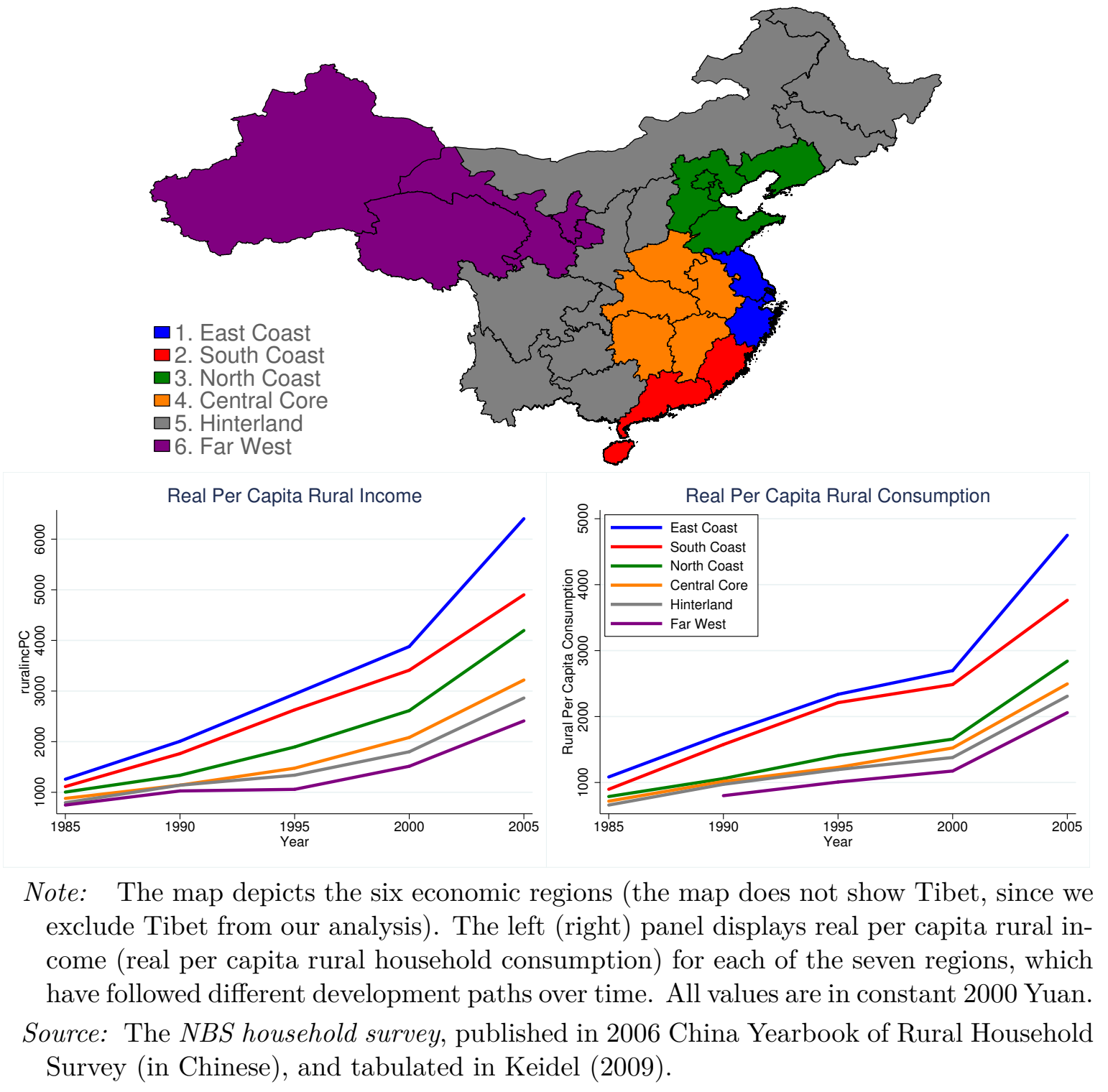


Figure A4: The distribution of terms over time

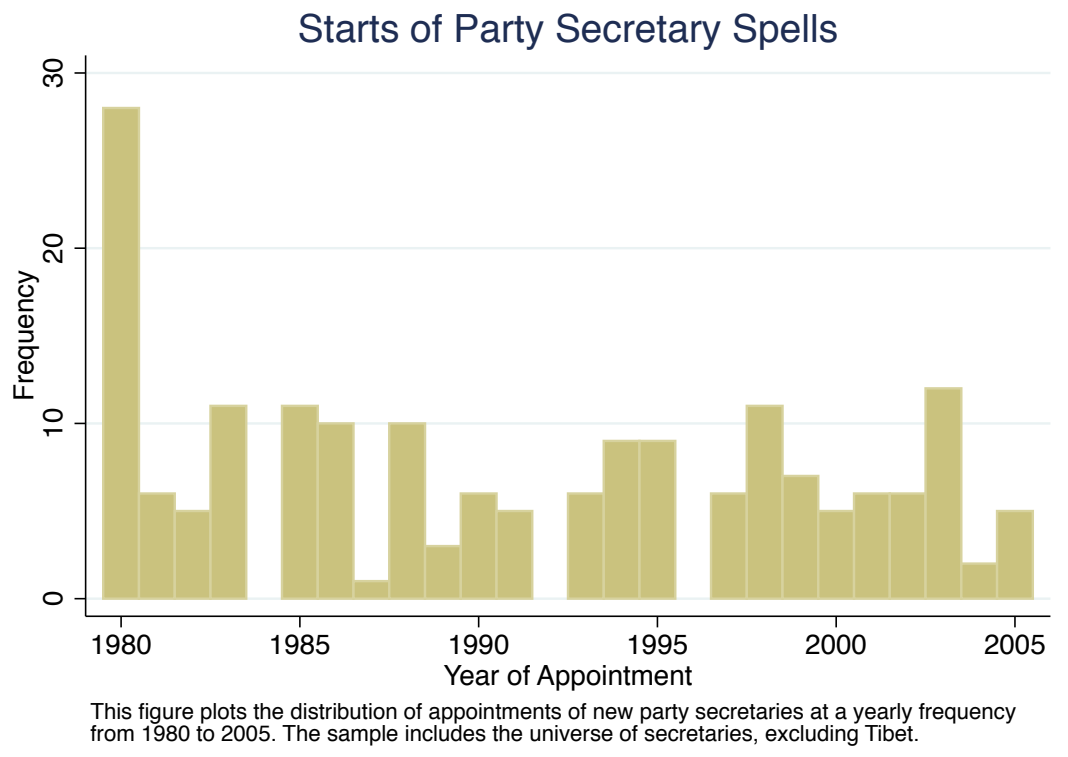


Figure A5: Outcomes by year around the expiration of incumbent party secretary terms
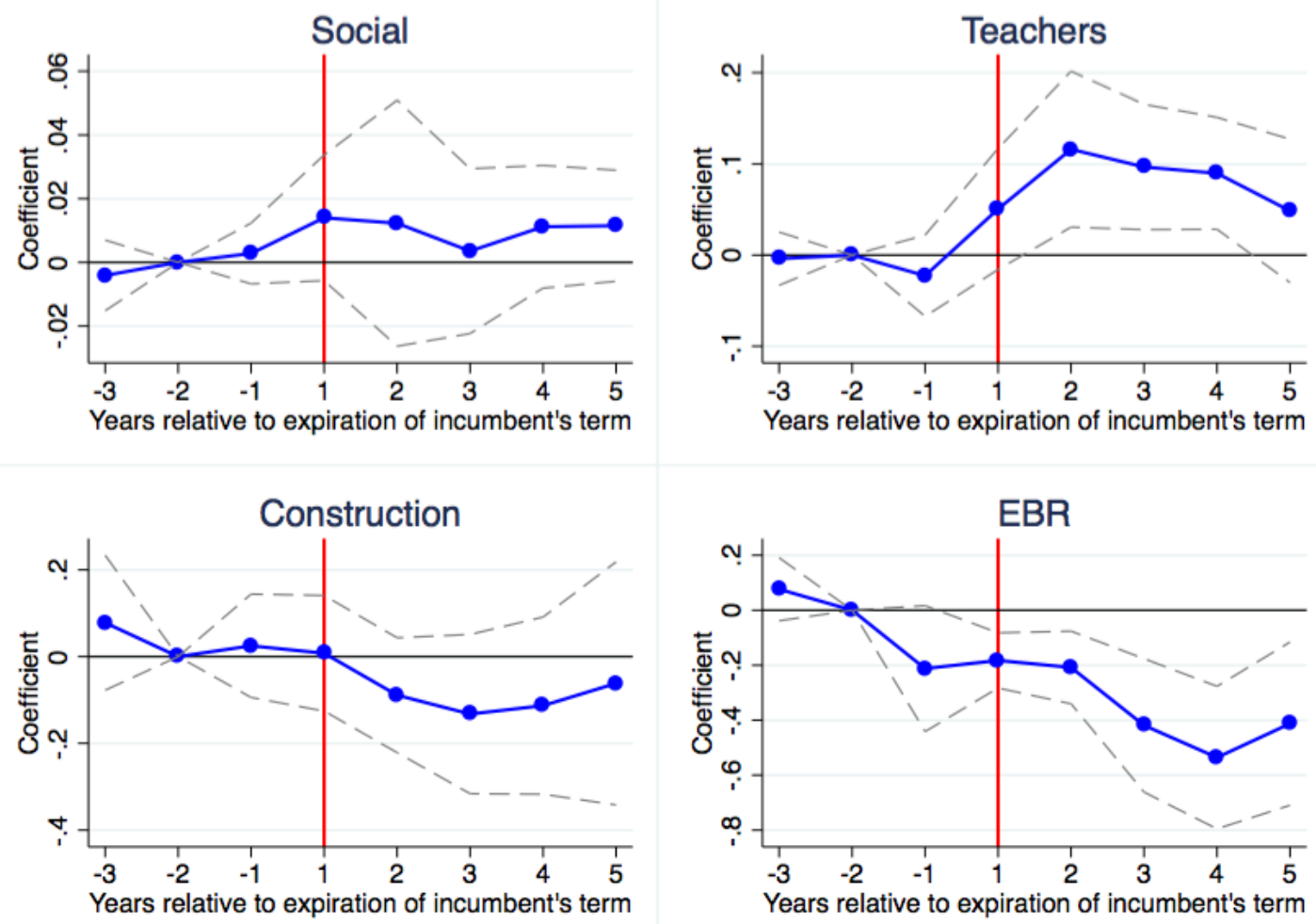

Note: The $x$-axis represents a timeline relative to the year of expiration of the five-year term of the party secretary who is incumbent at the time of a general secretary switch. Negative values on the $\mathrm{x}$-axis indicate the number of years before the expiration of the incumbent's term, and positive values represent the term-year of the subsequent five-year term. The solid vertical line indicates the first year after the expiration of the incumbent's five-year term. We regress of each of the four outcomes on $G s W o r k_{p t}$, indicator variables for each year on the timeline, and interactions between $G s W o r k_{p t}$ and each timeline dummy. The four panels present, for each outcome, the coefficients on the interaction terms, along with their confidence intervals, relative to the level two years before the expiration of the incumbent party secretary's term. These coefficients capture the change that occurs, in provinces where the general secretary worked, around the expiration of the incumbent's five-year term. All models include the set of controls displayed in Column 4 of Table 2, as well as province- and year FE and six economic region-specific time trends. Standard errors are clustered at the province level. 
Table A1: Summary statistics

\begin{tabular}{|c|c|c|c|c|c|}
\hline Description & Obs & Mean & Std. Dev. & Min & $\operatorname{Max}$ \\
\hline \multicolumn{6}{|l|}{ Backgrounds } \\
\hline Local $=$ worked both in high and low positions in prov. & 755 & 0.38 & 0.49 & 0 & 1 \\
\hline Worked in center & 755 & 0.48 & 0.50 & 0 & 1 \\
\hline Worked in center in high positions & 755 & 0.20 & 0.40 & 0 & 1 \\
\hline Worked in other provinces & 755 & 0.65 & 0.48 & 0 & 1 \\
\hline Worked in other prov. in high positions & 755 & 0.47 & 0.50 & 0 & 1 \\
\hline Worked elsewhere in high positions & 755 & 0.60 & 0.49 & 0 & 1 \\
\hline Did not work in this province & 755 & 0.39 & 0.49 & 0 & 1 \\
\hline Did not work in this prov. in high positions & 755 & 0.42 & 0.49 & 0 & 1 \\
\hline Politburo member & 755 & 0.10 & 0.30 & 0 & 1 \\
\hline Native province & 755 & 0.14 & 0.35 & 0 & 1 \\
\hline Has higher education & 753 & 0.64 & 0.48 & 0 & 1 \\
\hline \multicolumn{6}{|l|}{ Outcomes } \\
\hline Log of extra-budgetary revenue & 647 & 3.06 & 0.85 & 0.29 & 4.94 \\
\hline Social expenditure share & 697 & 0.25 & 0.042 & 0.13 & 0.38 \\
\hline Log of teachers in primary schools & 705 & 12.0 & 0.72 & 10.1 & 13.1 \\
\hline Log of construction output & 718 & 3.64 & 1.20 & 0.31 & 6.94 \\
\hline \multicolumn{6}{|l|}{ Controls } \\
\hline Age & 755 & 60.5 & 5.16 & 35 & 75 \\
\hline Tenure & 755 & 3.29 & 2.19 & 1 & 12 \\
\hline Higher education & 753 & 0.64 & 0.48 & 0 & 1 \\
\hline Native province & 755 & 0.14 & 0.35 & 0 & 1 \\
\hline Retirement limit & 755 & 0.11 & 0.31 & 0 & 1 \\
\hline Serves second term & 755 & 0.16 & 0.36 & 0 & 1 \\
\hline Worked in the center & 755 & 0.20 & 0.40 & 0 & 1 \\
\hline PS is Politburo member & 755 & 0.10 & 0.30 & 0 & 1 \\
\hline Marginal retention rate (MRR) & 755 & 0.91 & 0.20 & 0.085 & 1 \\
\hline Log population & 749 & 10.3 & 0.81 & 8.23 & 11.5 \\
\hline Log urbanization & 714 & -1.40 & 0.53 & -2.38 & -0.20 \\
\hline 1yr Lagged Log GPP & 755 & 5.76 & 1.06 & 2.63 & 8.28 \\
\hline GPP growth of predecessor & 750 & 0.091 & 0.033 & -0.058 & 0.21 \\
\hline Average GPP growth over spell until t & 755 & 0.088 & 0.033 & -0.064 & 0.27 \\
\hline \multicolumn{6}{|l|}{ Other variables } \\
\hline Urban-rural ratio of living exp. per cap & 729 & 2.53 & 0.64 & 1.17 & 4.71 \\
\hline Urban-rural ratio of GRP per employee & 716 & 4.61 & 1.91 & 1.55 & 16.8 \\
\hline Net fiscal transfer & 268 & 3.38 & 0.68 & 1.31 & 4.70 \\
\hline Provincial anti-corruption score, 1998-2003 & 180 & 3.33 & 0.86 & 2.02 & 5.46 \\
\hline Provincial gov. efficiency score, 1998-2003 & 180 & 0.000056 & 0.24 & -0.48 & 0.59 \\
\hline
\end{tabular}


Table A2: Correlation between extra-budgetary revenue and anti-corruption measures

\begin{tabular}{lccccc}
\hline Dependent variable: & \multicolumn{5}{c}{ Mean log extra-budgetary revenue } \\
& $(1)$ & $(2)$ & $(3)$ & $(4)$ & $(5)$ \\
\hline Anti-corruption score, 1998-2003 & $-0.109^{* *}$ & $-0.102^{* *}$ & & & $-0.0909^{*}$ \\
& $(0.0477)$ & $(0.0435)$ & & & $(0.0520)$ \\
Gov. efficiency score, 1998-2003 & & & -0.673 & -0.581 & -0.469 \\
& & & $(0.408)$ & $(0.398)$ & $(0.395)$ \\
Log population & -0.0836 & -0.208 & $-0.341^{*}$ & $-0.416^{* *}$ & $-0.396^{* *}$ \\
& $(0.0892)$ & $(0.137)$ & $(0.184)$ & $(0.193)$ & $(0.189)$ \\
1yr Lagged Log GPP & $1.064^{* * *}$ & $1.194^{* * *}$ & $1.283^{* * *}$ & $1.369^{* * *}$ & $1.353^{* * *}$ \\
& $(0.0801)$ & $(0.136)$ & $(0.150)$ & $(0.160)$ & $(0.169)$ \\
Eastern province dummy & & -0.182 & & -0.168 & -0.152 \\
& & $(0.139)$ & & $(0.120)$ & $(0.129)$ \\
\hline Number of observations & 29 & 29 & 29 & 29 & 29 \\
Adj. R-Squared & 0.94 & 0.94 & 0.94 & 0.94 & 0.94 \\
\hline
\end{tabular}

Source: The province-level anti-corruption and efficiency of government scores are obtained from Cole et al. (2008) for the years 1998 - 2003.

Note: The dependent variable in all regressions is average (log of) extra-budgetary revenue for the years 1998-2003. For the two scores, we use averages for the years 1998 - 2003 (intra-province variation is small); other controls are taken for the year 1997. 
Table A3: Definitions and sources of outcome variables

\begin{tabular}{|c|c|c|c|}
\hline Variable name & Outcome & Definition & Source \\
\hline$\overline{E B R}$ & Extra-budgetary revenue & $\begin{array}{l}\text { Log of extra-budgetary revenue consists of quasi-legal fees } \\
\text { levied by the sub-national governments: public utilities surcharges, } \\
\text { transportation and licence fees, and, to some extent, } \\
\text { retained earnings of local state-owned enterprizes (SOEs). } \\
\text { The World Bank describes these funds as arising from } \\
\text { "ad hoc fees and charges designed to tap deep pockets } \\
\text { wherever they exist, and enterprizes are prime targets." }\end{array}$ & $\begin{array}{l}\text { Difang caizheng tongji ziliao } \\
\text { (Local Public Finance Data) }\end{array}$ \\
\hline Social & Social expenditure share & Share of expenditure spent on culture, education, science and health. & Provincial yearbooks \\
\hline
\end{tabular}


Table A4: Complier characteristics

\begin{tabular}{lccc}
\hline & $\operatorname{Pr}[x(p t)=1]$ & $\operatorname{Pr}[x(p t)=1 \mid$ Complier $)]$ & $\begin{array}{c}\text { Relative likelihood } \\
\text { that complier } \\
\text { has characteristic }\end{array}$ \\
\hline Higher education & 0.64 & 0.54 & 0.87 \\
Last term before retirement & 0.19 & 0.04 & 0.22 \\
Worked in the center & 0.2 & 0.05 & 0.25 \\
PS is Politburo member & 0.1 & 0.02 & 0.22 \\
\hline
\end{tabular}

Table A5: $p$-values for the main results with alternative assumptions about clusters

\begin{tabular}{lcccc}
\hline & \multicolumn{4}{c}{ Panel A: OLS } \\
\cline { 2 - 4 } Dependent variable: & Social & Teachers & Construction & EBR \\
\hline Clusters by province & 0.021 & 0.106 & 0.069 & 0.033 \\
Wild cluster bootstrap & 0.0501 & 0.1682 & 0.1241 & 0.0581 \\
\hline \hline & & & Panel B: IV & EBR \\
\cline { 2 - 5 } Dependent variable: & Social & Teachers & Construction & 0.011 \\
\hline Clusters by province & 0.020 & 0.002 & 0.015 & EBR \\
\hline \hline & & Panel C: Reduced Form & $<0.0001$ \\
\hline Dependent variable: & Social & Teachers & Construction & 0.0120 \\
\hline Clusters by province & 0.004 & 0.043 & 0.002 & 0.0200 \\
\hline
\end{tabular}

Note: $p$-values from models using alternative assumptions on the variance-covariance matrix. The first row of each panel presents $p$-values obtained when standard errors are adjusted for one-way clusters at the province level. The second row (of Panels A and C) presents p-values from models using one-way clustering with wild bootstrapped standard errors (Cameron et al., 2008). All controls are as in column (4) of Table 2, and include province- and year fixed effects, as well as six economic region-specific time trends. 
Table A6: First stage and results controlling for province-specific time trends

\begin{tabular}{|c|c|c|c|c|}
\hline \multirow[t]{3}{*}{ Pre-trends } & \multicolumn{4}{|c|}{ First Stage } \\
\hline & (1) & $(2)$ & $(3)$ & $(4)$ \\
\hline & $\begin{array}{c}\text { Dependent variable: } \\
\text { PS is Local }\end{array}$ & $\begin{array}{c}\text { F-stat: } \\
\text { two-way clustering }\end{array}$ & $\begin{array}{l}\text { F-stat: } \\
\text { robust }\end{array}$ & Adj. R-Squarec \\
\hline GS Worked $\times$ Term Expires & $\begin{array}{l}0.229^{* * *} \\
(0.0876)\end{array}$ & 5.39 & 9.37 & 0.54 \\
\hline Mean, dept. var & 0.40 & & & \\
\hline \multirow[t]{2}{*}{ Number of observations } & 709 & & & \\
\hline & \multicolumn{4}{|c|}{ Panel A: OLS } \\
\hline Dependent variable: & Social & Teachers & Construction & EBR \\
\hline \multirow[t]{2}{*}{ PS is Local } & $0.00943^{* *}$ & 0.0155 & $-0.0723^{* *}$ & $-0.0333^{*}$ \\
\hline & $(0.00385)$ & $(0.0112)$ & $(0.0325)$ & $(0.0182)$ \\
\hline Controls & All & All & All & All \\
\hline \multirow[t]{2}{*}{ Within R-squared } & 0.74 & 0.65 & 0.97 & 0.88 \\
\hline & \multicolumn{4}{|c|}{ Panel B: IV } \\
\hline Dependent variable: & Social & Teachers & Construction & EBR \\
\hline PS is Local & $0.0714^{*}$ & 0.206 & -0.260 & -0.501 \\
\hline & $(0.0384)$ & $(0.163)$ & $(0.233)$ & $(0.331)$ \\
\hline \multirow[t]{2}{*}{ Controls } & All & All & All & All \\
\hline & \multicolumn{4}{|c|}{ Panel C: Reduced form } \\
\hline Dependent variable: & Social & Teachers & Construction & EBR \\
\hline GS Worked $\times$ Term Expires & $0.0181^{* * *}$ & $0.0482^{* *}$ & $-0.0627^{*}$ & $-0.129^{* * *}$ \\
\hline & $(0.00272)$ & $(0.0232)$ & $(0.0367)$ & $(0.0425)$ \\
\hline Controls & All & All & All & All \\
\hline Within R-squared & 0.74 & 0.65 & 0.97 & 0.88 \\
\hline Mean, dept. var & 0.26 & 11.97 & 3.61 & 3.07 \\
\hline Number of observations & 679 & 690 & 696 & 636 \\
\hline
\end{tabular}

Note: Standard errors are adjusted for two-way non-nested clusters, with the first dimension of clusters being province and the second dimension of clusters being the general secretary's career background during each party congress spell. All controls are as in column (4) of Table 2, and include province- and year FE as well as province-specific time trends. 
Table A7: Interaction with tenure on the job

\begin{tabular}{lcccc}
\hline & \multicolumn{3}{c}{ Panel A: OLS } \\
\cline { 2 - 5 } Dependent variable & Social & Teachers & Construction & EBR \\
\hline Party Secretary is Local & $0.00971^{* *}$ & $0.0169^{*}$ & $-0.0783^{*}$ & $-0.0660^{* *}$ \\
& $(0.00477)$ & $(0.00929)$ & $(0.0410)$ & $(0.0284)$ \\
PS is Local $\times$ & -0.000594 & -0.000748 & -0.0179 & -0.00412 \\
Tenure-mean) & $(0.000600)$ & $(0.00252)$ & $(0.0163)$ & $(0.0103)$ \\
Tenure & -0.000440 & 0.0000346 & 0.00487 & $0.01000^{* * *}$ \\
& $(0.000926)$ & $(0.00315)$ & $(0.0116)$ & $(0.00262)$ \\
\hline Controls & All & All & All & 0.80 \\
Within R-squared & 0.60 & 0.53 & 0.96 & EBR \\
\hline \hline & & & Panel B: IV & $-0.581^{* *}$ \\
Dependent variable & Social & Teachers & Construction & $(0.278)$ \\
\hline Party Secretary is Local & $0.0456^{* * *}$ & 0.146 & $-0.487^{* * *}$ & -0.0664 \\
PS is Local $\times$ & $(0.0149)$ & $(0.126)$ & $(0.0524)$ & $(0.159)$ \\
(Tenure-mean) & 0.0117 & 0.0575 & -0.163 & 0.0474 \\
Tenure & $(0.00968)$ & $(0.103)$ & $(0.117)$ & $(0.0961)$ \\
\hline Controls & -0.00728 & -0.0335 & 0.0860 & All \\
\hline \hline Number of observations & $(0.00659)$ & $(0.0616)$ & $(0.0774)$ & 636 \\
\hline
\end{tabular}

Note: Standard errors are adjusted for two-way non-nested clusters, with the first dimension of clusters being province and the second dimension of clusters being the general secretary's career background during each party congress spell. All models includes the set of controls displayed in Column 4 of Table 2, as well as province- and year FE and six economic region-specific time trends. 
Table A8: Promotion mechanism, policy outcomes, and career backgrounds: interactions

\begin{tabular}{|c|c|c|c|c|}
\hline \multirow{3}{*}{ Dependent variable: } & \multicolumn{4}{|c|}{ Panel A: no controls for growth performance } \\
\hline & \multicolumn{4}{|c|}{$0=$ demoted $; 1=$ same-level position; $2=$ promoted } \\
\hline & (1) & $(2)$ & (3) & $(4)$ \\
\hline PS is Local & $\begin{array}{r}-0.0201 \\
(0.100)\end{array}$ & $\begin{array}{l}-0.115 \\
(0.124)\end{array}$ & $\begin{array}{l}-0.0880^{*} \\
(0.0460)\end{array}$ & $\begin{array}{l}-0.0918 \\
(0.0597)\end{array}$ \\
\hline Social (Avg.) & $\begin{array}{c}0.464 \\
(0.380)\end{array}$ & & & \\
\hline Social $($ Avg.) $\times$ Local & $\begin{array}{c}-0.0760 \\
(0.392)\end{array}$ & & & \\
\hline Teachers Per Capita (Avg.) & & $\begin{array}{c}0.0905 \\
(0.0595)\end{array}$ & & \\
\hline Teachers Per Capita (Avg.) × Local & & $\begin{array}{c}0.0446 \\
(0.0736)\end{array}$ & & \\
\hline Construction (Avg.) & & & $\begin{array}{l}0.0622^{* *} \\
(0.0301)\end{array}$ & \\
\hline Construction (Avg.) $\times$ Local & & & $\begin{array}{c}0.0129 \\
(0.0140)\end{array}$ & \\
\hline EBR (Avg.) & & & & $\begin{array}{c}0.0348 \\
(0.0308)\end{array}$ \\
\hline EBR (Avg.) $\times$ Local & & & & $\begin{array}{c}0.0206 \\
(0.0212)\end{array}$ \\
\hline Observations & 1313 & 1325 & 1332 & 1248 \\
\hline \multirow{3}{*}{ Dependent variable: } & \multicolumn{4}{|c|}{ Panel B: Controls for growth performance } \\
\hline & \multicolumn{4}{|c|}{$0=$ demoted $; 1=$ same-level position $; 2=$ promoted } \\
\hline & (1) & $(2)$ & $(3)$ & $(4)$ \\
\hline Average GPP Growth & $\begin{array}{l}0.726^{* *} \\
(0.283)\end{array}$ & $\begin{array}{l}0.860^{* * *} \\
(0.270)\end{array}$ & $\begin{array}{l}0.659^{* *} \\
(0.274)\end{array}$ & $\begin{array}{l}0.825^{* *} \\
(0.383)\end{array}$ \\
\hline PS is Local & $\begin{array}{r}-0.0377 \\
(0.104)\end{array}$ & $\begin{array}{l}-0.151 \\
(0.134)\end{array}$ & $\begin{array}{l}-0.0901^{*} \\
(0.0464)\end{array}$ & $\begin{array}{l}-0.0818 \\
(0.0612)\end{array}$ \\
\hline Social (Avg.) & $\begin{array}{c}0.321 \\
(0.403)\end{array}$ & & & \\
\hline Social $($ Avg. $) \times$ Local & $\begin{array}{c}-0.0214 \\
(0.406)\end{array}$ & & & \\
\hline Teachers Per Capita (Avg.) & & $\begin{array}{c}0.0934 \\
(0.0650)\end{array}$ & & \\
\hline Teachers Per Capita (Avg.) × Local & & $\begin{array}{c}0.0646 \\
(0.0787)\end{array}$ & & \\
\hline Construction (Avg.) & & & $\begin{array}{c}0.0583^{*} \\
(0.0298)\end{array}$ & \\
\hline Construction (Avg.) $\times$ Local & & & $\begin{array}{c}0.0129 \\
(0.0142)\end{array}$ & \\
\hline EBR (Avg.) & & & & $\begin{array}{c}0.0484 \\
(0.0322)\end{array}$ \\
\hline EBR (Avg.) $\times$ Local & & & & $\begin{array}{c}0.0159 \\
(0.0218)\end{array}$ \\
\hline Observations & 1313 & 1325 & 1332 & 1248 \\
\hline
\end{tabular}

$* \mathrm{p}<0.10, * * \mathrm{p}<0.05, * * * \mathrm{p}<0.01$.

Note: Marginal effects from Probit regressions with the deppendent variable taking the value of 0 , if the the provincial leader was demoted in year $t+1$ in province $p ; 1$, if he 5 remained in the same-level position in year $t+1$; and 2 , if he was promoted. This table replicates Table 5, but adds, for each of the four policy outcomes, an interaction of the outcome variable and whether a leader is local. The independent variable definitions, as well as all controls, are as in Table 5. Standard errors are clustered at the province level. 
Table A9: The impact of general secretary work experience on provincial governance

\begin{tabular}{lcccc}
\hline & \multicolumn{4}{c}{ OLS, sub-sample of PS - outsider } \\
\cline { 2 - 5 } & $(1)$ & $(2)$ & $(3)$ & $(4)$ \\
Social & Teachers & Construction & EBR \\
\hline General secretary & -0.00305 & $0.0478^{* *}$ & -0.0580 & 0.0740 \\
worked in province & $(0.00596)$ & $(0.0210)$ & $(0.0607)$ & $(0.0545)$ \\
Baseline controls & Yes & Yes & Yes & Yes \\
\hline Number of observations & 406 & 408 & 416 & 375 \\
\hline
\end{tabular}

Note: Subsample of province-year observations with outsider party secretary. Standard errors are adjusted for two-way non-nested clusters, with the first dimension of clusters being province and the second dimension of clusters being the general secretary's career background during each party congress spell. All controls are as in column (4) of Table 2, and include province- and year fixed effects, as well as six economic region-specific time trends.

\section{B An illustrative model of elite influence}

Our leading interpretation of the evidence on the alternative mechanisms is that locals' behave differently from outsiders because they cater to local low-level elites. Catering to elites can only benefit the population if favors to elites, at least to some extent, spill over to, and hence also benefit, the general population. Here, we formalize this interpretation and show under what conditions elite influence can be beneficial or harmful for governance.

\section{B.1 Setup}

Provincial resource allocation There are two time periods. In the first period, provincial budgetary resources can be put to two types of productive use-government infrastructure investment and social spending - or diverted by the provincial leader for private use.

(i) Government investments, such as construction or infrastructure, yield an immediate boost to provincial growth and contribute to future growth. We denote these investments by $c$, and refer to them as construction. Formally, we assume that a one yuan investment into $c$ yields a contribution to first-period provincial growth given by $y_{1}^{c}=f_{c}(c)+\varepsilon$, and a contribution to second-period growth, $y_{2}^{c}=f_{c}(c)$, where $\varepsilon \sim N\left(0, \sigma^{2}\right)$ and where $f_{c}(\cdot)$ is strictly concave, satisfies the condition $f_{c}^{\prime}(\cdot) \rightarrow \infty$ as 
$c \rightarrow 0$, and has the property that $f_{c}^{\prime}(c) / f_{c}^{\prime}(1-c)$ is strictly convex. ${ }^{32}$ Here, $\varepsilon$ reflects that growth coming from the short-term investment is uncertain in the first period. ${ }^{33}$

(ii) Social spending, such as expenditure on education and health care, does not yield any tangible growth benefits in the first period, but may be growth-promoting in the long run (by the second period). We denote these social expenditures by $s$. A one yuan investment into $s$ yields a contribution to second-period growth, $y_{2}^{s}=f_{s}(s)$, where $f_{s}(\cdot)$ satisfies the same conditions. The key assumption here is that social expenditure yields no contribution to growth in the short run. It is not necessary for these expenditures to be growth promoting in the longer run, they could simply capture spending that yields other benefits to the population that does not translate into economic growth.

(iii) Provincial resources that are diverted by the provincial leader, $e$, generate no growth and yield a private benefit $g(e)$ to the provincial leader (or to the person(s) the leader transfers these resources to).

Social benefits from spending on construction or social expenditure are much higher than the private benefits from diversion. Formally, $f_{c}(\cdot)=k_{c} g(\cdot)$ and $f_{s}(\cdot)=k_{s} g(\cdot)$, where $k_{c}$ and $k_{s}$ are constants satisfying $k_{c}, k_{s}>>1 .^{34}$

Normalizing total resources to one, the resource constraint is $1=c+s+e$. Any rent extraction $(e>0)$ indirectly harms society as it amounts to a reduction of the resources that are put to productive use.

Uninfluenced party secretary (outsider) The party secretary is appointed for one period and lives (pursues a career) for two periods. In the first period, he decides how to allocate provincial budget resources between $c, s$, and $e$.

At the end of the first period, the party secretary is evaluated by the central government, and he is either demoted or promoted. We assume, for simplicity, that the discounted value

\footnotetext{
${ }^{32}$ These assumptions on $f_{c}(c)$ are satisfied by standard concave functions such as $f_{c}(c)=\ln c$, and $f_{c}(c)=$ $\sqrt{c}$, but are more general.

${ }^{33}$ As we discuss in the proofs below, for technical reasons, we assume that $\varepsilon$ is not too low. This is arguably consistent with the reality facing Chinese provincial leaders.

${ }^{34}$ This is reasonable as it is commonly believed that public goods such as education and health care were under-provided in China during the analyzed time period (Luo et al., 2010; Whiting, 1996).
} 
of being promoted is $P .{ }^{35}$ The central government uses a performance-based promotion rule whereby the party secretary is promoted if provincial growth during his tenure (Period 1) exceeds some growth target, $\bar{y}$. The focus of the central government on economic growth was not only stated explicitly, but also established empirically in Li and Zhou (2005), and Chen et al. (2005), who show that the probability of promotion or demotion of a provincial leader is significantly affected by the average provincial growth during the secretary's tenure.

Because the center wants to re-evaluate party secretaries every five years, the growth target must be set in relation to the observable output by this time. Thus, in model terms, the growth target is set so as to maximize provincial growth-promoting investment in the first period, $c$.

Even if the government were to desire a mix of construction and social spending $(c$ and $s)$, it is not possible for the center to simultaneously engage in performance-based promotion and encourage investment in $s$, as any proceeds from $s$ are realized after the decision to demote or promote the party secretary is taken. Thus, if the central government wants to use career concerns to weaken the party secretary's incentives to engage in rent extraction, it is necessary to reward the party secretary for short-term growth-enhancing policies, at the expense of policies that translate into growth in the longer run. ${ }^{36}$

A party secretary who is uninfluenced by the provincial elite (henceforth an outsider) trades off career concerns and the desire to extract rents for himself, $e_{1}$. He chooses $c, s$, and $e$ so as to maximize his expected utility, given by

$$
U^{\text {Outsider }}=\operatorname{Pr}\left(y_{1}>\bar{y}\right) P+g\left(e_{1}\right)=\operatorname{Pr}\left(f_{c}(c)+\varepsilon>\bar{y}\right) P+g\left(e_{1}\right) .
$$

General population We assume that the general population wants to implement the socially optimal allocation, that is, allocate the resources so as to maximize growth over the two time periods. In Period 1, the total discounted expected benefit from a one yuan investment into $c$ is given by $y_{1}^{c}+\delta y_{2}^{c}=(1+\delta) f_{c}(c)$, and the corresponding benefit from $s$ is given by $\delta y_{2}^{s}=\delta f_{s}(s)$, where $\delta$ is the discount factor, which we normalize to one. Because the

\footnotetext{
${ }^{35}$ Here, promotion is defined broadly as non-demotion; that is, it encompasses reappointment, rotation to another province or to the central government, and promotion to the Politburo.

${ }^{36}$ Note that a consistent use of a promotion mechanism that rewards growth in the short run, for example, over 5-year terms of Party Secretary appointments, theoretically translates into growth in the longer run.
} 
party secretary's rent extraction yields no growth, the general population wants to eliminate it completely. The general population, thus, maximizes the expected utility

$$
U^{\text {Population }}=y_{1}^{c}+y_{2}^{c}+y_{2}^{s}=2 f_{c}(c)+f_{s}(s) .
$$

Alternatively, we can assume that the general population has direct preferences over $c$ and $s$ while $s$ is not necessarily growth-promoting. All the main results of the model will go through with this alternative assumption.

Provincial elites We aim at analyzing how the party secretary's optimal budget allocation and rent extraction change when he is affiliated with the provincial elites. We model the preferences of the provincial elites as

$$
U^{\text {Elite }}=g\left(e_{2}\right)+\theta U^{\text {Population }}
$$

where $e_{2}$ are transfers from the party secretary, and $\theta \in\{0,1\}$. This formulation captures two important aspects of the provincial elites. First, elites value any transfers, $e_{2}$, which they may receive from the party secretary. If an influenced party secretary transfers resources to the elite, these must be diverted from the provincial budget resources. Second, we allow for a varying degree of similarity between the provincial elites and the general population. The parameter $\theta$ reflects the similarity between provincial elite and the general population: If $\theta=0$, the provincial elite cares solely about rents and has nothing in common with the general population. If $\theta=1$, the provincial elite values any private transfers that it may receive, but is otherwise similar to the general population. We analyze the effect of elite influence in these two extreme cases separately.

The latter case, $\theta=1$, is not to be taken literally - it is highly unlikely that the elite will have preferences that are perfectly aligned with the general population. We analyze this extreme case only because it is the simplest way to capture the benefits of elite influence. In reality, we would expect $\theta$ to lie strictly within the interval $\theta \in(0,1)$. Below we also discuss this case. 
Elite influence We model the preferences of a local party secretary, who is influenced by local elites, as

$$
U^{\text {Local }}=U^{\text {Outsider }}+\rho U^{\text {Elite }},
$$

where $\rho>0$. The local party secretary must balance his own career concerns (which he shares with outsiders) with an inclination to cater to the interests of the provincial elites. When $\rho=1$, he weighs the two objectives equally, while his career concerns dominate whenever $\rho<1$. For simplicity, we will let $\rho=1$.

The local party secretary allocates the provincial resources between the two productive uses, $c$ and $s$, rent diversion for himself, $e_{1}$, and diversion of rents that he transfers to the provincial elite, $e_{2}$. We compare the optimal choices of a local party secretary with those of an outsider party secretary.

\section{B.2 Elite influence: Subversion vs. Substitute for democracy}

First, we analyze an outsider's optimal allocation of provincial budget resources. Then, we show how this allocation changes if an outsider party secretary is replaced by a local party secretary. All proofs are in the Section B.3.

As the outsider is evaluated solely based on growth during Period 1, he sets social spending to zero. Instead, he divides provincial resources between construction and rent diversion. His

optimal resource allocation $\left(c^{O}, s^{O}, e^{O}\right)$ satisfies $1=c^{O}+e^{O}$, where $e^{O}=e_{1}^{O}$. In contrast, the general population's optimal resource allocation $\left(c^{*}, s^{*}, e^{*}\right)$ is a mix of construction and social expenditure, $1=c^{*}+s^{*}$.

Proposition 1. From the general population's perspective, the outsider under-invests in social expenditure $\left(s^{*}>s^{O}\right)$ and engages in wasteful rent extraction $\left(e^{*}<e^{O}\right)$. The outsider's rent extraction, $e^{O}$, is decreasing in $P$ and increasing in $\sigma^{2}$.

In words, the outsider under-invests in social expenditure because he balances two objectives: staying in office and extracting rents. Career concerns induce him to make short-term investments in construction. The outsider party secretary may allocate more or less to construction than the general population would optimally choose; that is, $c^{O} \gtrless c^{*}$. However, as the outsider spends any remaining yuan on rent extraction rather than on social expenditure, 
the general population is better off the higher is $c^{O}$. The outsider will appropriate less resources when the value of promotion $(P)$ is high. A lower unpredictability of the first-period growth $\left(\sigma^{2}\right)$ strengthens the outsider's incentive to invest in this good, and hence reduces rent extraction. ${ }^{37}$

This theoretical result for outsiders behavior under the promotion mechanism that rewarded (short-term) growth over the party secretary term is consistent with the fact that it is commonly believed that public goods such as education and health care in China were under-provided during the time period characterized by strong emphasis on short-term economic performance in promotion decisions (Whiting, 1996; Luo et al., 2010).

Now, we ask how the optimal resource allocation changes if an outsider party secretary is replaced by a local party secretary.

Proposition 2 (Subversion). When the provincial elite has nothing in common with the general population, $\theta=0$, elite influence leads to subversion: Replacing an outsider with a local party secretary (i) increases rent extraction $\left(e^{\theta=0}>e^{O}\right)$, (ii) reduces construction $\left(c^{\theta=0}<c^{O}\right)$, and (iii) does not increase social expenditure $\left(s^{\theta=0}=s^{O}\right)$. As a result, economic growth decreases, both in the short and the long run.

Intuitively, if the provincial elite has nothing in common with the general population, elite influence only strengthens the party secretary's incentives to divert provincial resources away from productive uses. While an outsider only has an incentive to divert resources for his own private use, a local party secretary also channels resources to the provincial elite, which further crowds out investment in construction, and, consequently, reduces growth.

Proposition 3 (Substitute for democracy). When the provincial elite is similar to the general population and social spending is desirable by the population ( $k_{s}$ high), elite influence represents a substitute for democracy: Replacing an outsider with a local party secretary (i) reduces rent extraction $\left(e^{\theta=1}<e^{O}\right)$ and (ii) increases social expenditure $\left(s^{\theta=1}>s^{O}\right)$, whereas (iii) construction may increase or decrease $\left(c^{\theta=1} \lessgtr c^{O}\right)$. The effect on economic growth is ambiguous in the short run. In the long run, the effect on growth is positive under the assumption that social spending is productive in the long run, otherwise, it is also ambiguous.

\footnotetext{
${ }^{37}$ As growth is uncertain, the party secretary will not be promoted with certainty at his optimal resource allocation.
} 
Here we consider the extreme case when $\theta=1$. In this case, the provincial elite is similar to the general population (except that it desires side transfers from the party secretary). Then, replacing an outsider with a local party secretary has very different consequences than from the subversion case discussed above. In particular, in this case, in contrast to an outsider, a local party secretary allocates some funds to social expenditure, although such investments confer no career benefit to him. Because the benefits that the local party secretary provides to the provincial elite spill over to the general population, elite influence can represent a substitute for local democracy in this case. Replacing an outsider with a local party secretary decreases rent extraction and increases investments in education and health care, both of which represent a shift of provincial policies closer to the general population's optimal resource allocation. The effect of elite influence on growth in the short-run is ambiguous because it depends on the level of investment in construction. In the long run, growth increases if social spending is growth-promoting because elite influence reduces the under-investment in education and healthcare. If social spending does not yield growth in the long run, growth implications of elite influence are ambiguous in the long run as well. Most importantly, the general population is better off under local party secretary when $\theta=1$.

Allowing $\theta$ to be continuous So far we have considered the two extreme cases of $\theta=0$ (no alignment between the elite and the population) and $\theta=1$ (perfect alignment). This analysis in fact informs us of what would happen in the (more likely) case when $\theta$ is continuous: as $\theta$ would rise from 0 to 1 , the elite would gradually become more representative of the population. Hence, elite capture would gradually become more beneficial, by moving the implemented policy closer and closer to the bliss point of the population. Importantly, already for a small $\theta$, some benefits begin to spill over to the population; hence, elite capture can constitute a substitute for accountability even if the elite is not fully aligned with the masses. We illustrate this logic in Figure B6 below. 
Figure B6: Elite influence as subversion or accountability

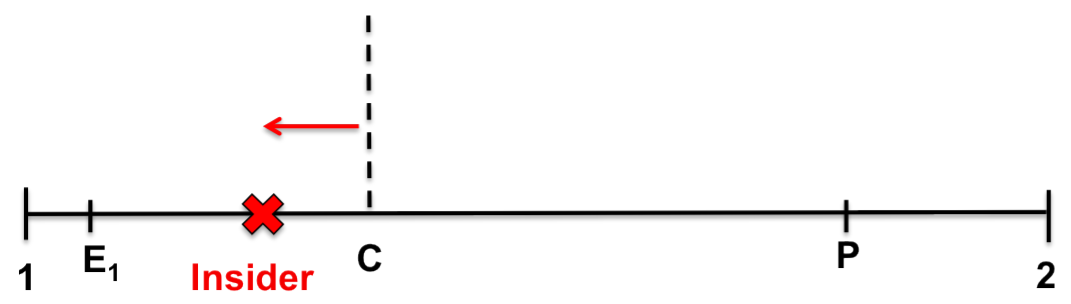

\section{Subversion}

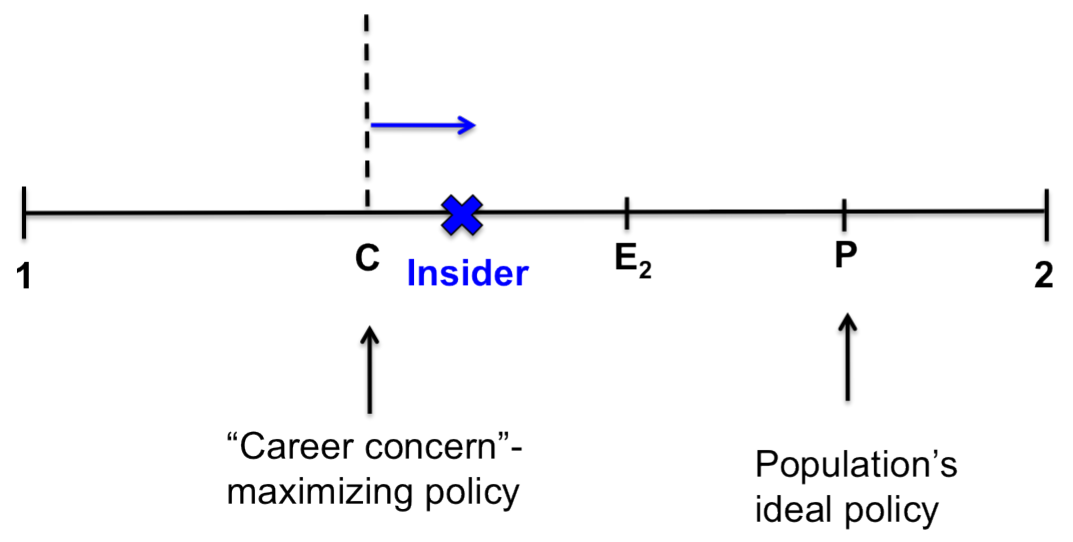

Accountability

Chosen by outsider

Note: The continuum $[1,2]$ depicts a policy space where each point represents an allocation of fiscal resources between needs 1 and 2. $C$ denotes the policy choice that maximizes the politician's future career prospects. $C$ is chosen by a politician who is solely career concerned (in our empirical context, an outsider). In a democratic setting with full accountability, $C$ can be expected to lie close to, or coincide with, some aggregation of the population's preferences. In a non-democratic context, however, $C$ is determined through the central promotion mechanism, and hence $C$ need not coincide with the population's bliss point. The figure illustrates such a case, with $P \neq C$ denoting the population's preferences. Further, $E_{1}$ and $E_{2}$ represent two examples of elite preferences. The upper panel illustrates how a captured politician's policy choice is affected by catering to Elite 1: because the policy shift towards the elite represents a shift away from $C$ and further away from $P$, elite influence is harmful, and subversion arises. The lower panel, however, illustrates how a captured politician's policy choice is affected by catering to Elite 2: because the policy shift towards the elite represents a shift away from $C$ but towards $P$, elite influence is beneficial, and constitutes a substitute for accountability. This arises so long as Elite 2's bliss point lies between $C$ and $P$, and does not require Elite 2 being aligned with $P$. Note that, in a democratic setting, any deviation from $C$ is harmful, and hence elite capture always constitutes subversion. 


\section{B.3 Proofs}

\section{Proposition 1}

Outsider party secretary The outsider party secretary maximizes his expected utility:

$$
\max _{c, s, e}\left\{\operatorname{Pr}\left(y_{1}>\bar{y}\right) P+g\left(e_{1}\right)\right\}
$$

subject to the resource constraint $1=c+s+e_{1}$. Because he is evaluated solely based on growth during Period 1, $y_{1}$, the outsider invests nothing in the long-term productive good, i.e., $s^{O}=0$.

We substitute $y_{1}=f_{c}(c)+\varepsilon$ and $1=c+e_{1}$ into the maximand and rewrite the problem as

$$
\max _{c}\left\{\left[1-\Phi\left(\bar{y}-f_{c}(c)\right)\right] P+g(1-c)\right\}
$$

where $\Phi$ denotes the cumulative density of the Normal distribution. The first-order condition is

$$
\phi\left(\bar{y}-f_{c}(c)\right) P=\frac{g^{\prime}(1-c)}{f_{c}^{\prime}(c)},
$$

where $\phi$ denotes the density of the Normal distribution. Because $f_{c}^{\prime}(c)=k_{c} g^{\prime}(c)$, the righthand side of (6) is strictly convex in $c$, and increases from zero to infinity as $c$ increases from zero to one. The left-hand side is a finite number; in fact, it is at most equal to $P / \sqrt{2 \pi \sigma^{2}}$

- Hence, (6) has at least one solution. Moreover, when $\sigma^{2}$ is large (as we assume), the right-hand side only intersects the bell-shaped left-hand side once; that is, (6) has a unique solution. Equilibrium investment into $c$ is the highest (and, thus, extraction $e$ is the smallest) when the right-hand side intersects the bell-shaped curve on the left-hand side at its highest point.

Note that variation in $\bar{y}$ corresponds to shifting the bell-shaped curve horizontally. Thus, the CCP can maximize short-term investment $c$ by optimally choosing $\bar{y}$, in which case the equilibrium level of short-term investment, $c^{O}$, satisfies $\bar{y}=f_{c}\left(c^{O}\right)$. Thus, (6) can be written

$$
\frac{P}{\sqrt{2 \pi \sigma^{2}}}=\frac{g^{\prime}(1-c)}{k_{c} g^{\prime}(c)}
$$


and the outsider's optimal choice $c^{O} \in(0,1)$ is the unique solution to this equation. The outsider's optimal allocation is $\left(c^{O}, s^{O}, e^{O}: 1=c^{O}+e_{1}^{O}\right)$. The fact that the right-hand side of (7) is increasing in $c$ immediately yields that $c^{O}$ is increasing in $P$ and decreasing in $\sigma^{2}$.

General population The general population's problem is

$$
\max _{c, s}\left\{2 f_{c}(c)+f_{s}(s)\right\}
$$

subject to $1=c+s$. The first-order condition is

$$
2 f_{c}^{\prime}(c)=f_{s}^{\prime}(1-c)
$$

Dividing both sides of (9) by $f_{c}^{\prime}(c)$ and applying an argument analogous to the one above yields that a unique interior solution $c^{*}$ exists. The general population's optimal allocation is $\left(c^{*}, s^{*}: 1=c^{*}+s^{*}\right)$.

\section{Proposition 2}

The captured party secretary solves

$$
\max _{c, s, e_{1}, e_{2}}\left\{U^{\text {Outsider }}+U^{\text {Elite }}\right\}
$$

subject to the constraint $1=c+s+e_{1}+e_{2}$. When $\theta=0$, we can re-write the maximand as

$$
\max _{c, s, e_{1}, e_{2}}\left\{\operatorname{Pr}\left(f_{c}(c)+\varepsilon>\bar{y}\right) P+g\left(e_{1}\right)+g\left(e_{2}\right)\right\} .
$$

Claim iii of Proposition 2: As $s$ does not enter the captured party secretary's expected utility, we have that $s^{\text {Subvertion }}=0$.

Thus, the resource constraint is $1=c+e_{1}+e_{2}$. We substitute this constraint into the maximand and obtain the following problem of the captured party secretary:

$$
\max _{c, e_{2}}\left\{\left[\left(1-\Phi\left(\bar{y}-f_{c}(c)\right)\right) P+g\left(1-c-e_{2}\right)\right]+g\left(e_{2}\right)\right\}
$$


The first-order condition w.r.t. $c$ is

$$
\operatorname{phi}\left(\bar{y}-f_{c}(c)\right) P=\frac{g^{\prime}\left(1-c-e_{2}\right)}{k_{c} g^{\prime}(c)}
$$

and w.r.t. $e_{2}$, is

$$
g^{\prime}\left(e_{2}\right)=g^{\prime}\left(1-c-e_{2}\right)
$$

Because $g^{\prime}(c) \rightarrow \infty$ as $c \rightarrow 0$, it follows from (14) that $e_{2}^{\theta=0}>0$; moreover, by the resource constraint, $e_{1}^{\theta=0}=e_{2}^{\theta=0}>0$. Applying an argument analogous to the one above yields that a unique interior solution exists to (13), and that the CCP can maximize short-term investment (and thus make appropriation $e_{1}^{\theta=0}+e_{2}^{\theta=0}$ as small as possible), by optimally choosing $\bar{y}$ such that the equilibrium level of short-term investment, $c^{\theta=0}$, satisfies $\bar{y}=f_{c}\left(c^{\theta=0}\right)$. Thus, (13) can be written

$$
\frac{P}{\sqrt{2 \pi \sigma^{2}}}=\frac{g^{\prime}\left(1-c^{\theta=0}-e_{2}^{\theta=0}\right)}{k_{c} g^{\prime}\left(c^{\theta=0}\right)} .
$$

Claim ii of Proposition 2: To show that the subverted party secretary allocates less resources to $c$ than an outsider party secretary (i.e., to show that $c^{\theta=0}<c^{O}$ ), we compare with the outsider party secretary's optimal choice of $c$, which by (6) satisfies

$$
\frac{P}{\sqrt{2 \pi \sigma^{2}}}=\frac{g^{\prime}\left(1-c^{O}\right)}{k_{c} g^{\prime}\left(c^{O}\right)} .
$$

For any $e_{2}>0$ and for any $c$, we have that $1-c-e_{2}<1-c$. Thus, as $g(\cdot)$ is concave, we have that $g^{\prime}\left(1-c-e_{2}\right)>g^{\prime}(1-c)$. Hence, $\frac{g^{\prime}\left(1-c-e_{2}\right)}{k_{c} g^{\prime}(c)}>\frac{g^{\prime}(1-c)}{k_{c} g^{\prime}(c)}$. Because $e_{2}^{\theta=0}>0$, it hence follows that $c^{\theta=0}<c^{O}$.

Claim i of Proposition 2: We now show that a captured party secretary appropriates more resources for private use than an outsider $\left(e_{1}^{\theta=0}+e_{2}^{\theta=0}>e^{O}\right)$ : Because $c^{\theta=0}<c^{O}$ and $s^{\theta=0}=s^{O}$, the captured party secretary puts less resouces to productive use than the outsider party secretary. All resources which are not put to productive use are extracted; that is, $1-c^{\theta=0}=e_{1}^{\theta=0}+e_{2}^{\theta=0}$ and $1-c^{O}=e^{O}$. Hence, $c^{\theta=0}<c^{O}$ implies that $e_{1}^{\theta=0}+e_{2}^{\theta=0}>e^{O}$. 


\section{Proposition 3}

The captured party secretary solves

$$
\max _{c, s, e_{1}, e_{2}}\left\{U^{\text {Outsider }}+U^{\text {Elite }}\right\}
$$

subject to the constraint $1=c+s+e_{1}+e_{2}$. We can re-write the maximand as

$$
\max _{c, s, e_{1}, e_{2}}\left\{\operatorname{Pr}\left(f_{c}(c)+\varepsilon>\bar{y}\right) P+g\left(e_{1}\right)+g\left(e_{2}\right)+2 f_{c}(c)+f_{s}(s)\right\}
$$

We substitute the resource constraint into the maximand and obtain the following problem of the captured party secretary:

$$
\max _{c, s, e_{2}}\left\{\left[\left(1-\Phi\left(\bar{y}-f_{c}(c)\right)\right) P+g\left(1-c-s-e_{2}\right)\right]+g\left(e_{2}\right)+2 f_{c}(c)+f_{s}(s)\right\}
$$

The first-order condition w.r.t $c$ is given by

$$
\operatorname{phi}\left(\bar{y}-f_{c}(c)\right) P f_{c}^{\prime}(c)-g^{\prime}\left(1-c-s-e_{2}\right)+2 f_{c}^{\prime}(c)=0,
$$

w.r.t. $s$ is given by

$$
f_{s}^{\prime}(s)=g^{\prime}\left(1-c-s-e_{2}\right)
$$

and w.r.t $e_{2}$ is given by

$$
g^{\prime}\left(e_{2}\right)=g^{\prime}\left(1-c-s-e_{2}\right)
$$

We re-write (20) as

$$
\phi\left(\bar{y}-f_{c}(c)\right) P+2=\frac{g^{\prime}\left(1-c-s-e_{2}\right)}{k_{c} g^{\prime}(c)}
$$

Applying an argument analogous to the one above yields that a unique interior solution exists to $(23)$, and that the CCP can maximize short-term investment by optimally choosing $\bar{y}$ such that the equilibrium level of short-term investment, $c^{\theta=1}$, satisfies $\bar{y}=f_{c}\left(c^{\theta=1}\right)$. Thus, (23) can be written

$$
\frac{P}{\sqrt{2 \pi \sigma^{2}}}+2=\frac{g^{\prime}\left(1-c^{\theta=1}-s^{\theta=1}-e_{2}^{\theta=1}\right)}{k_{c} g^{\prime}\left(c^{\theta=1}\right)} .
$$


Conditions (21) to (24) yield that the captured party secretary's optimal allocation satisfies

$$
g^{\prime}\left(e_{1}^{\theta=1}\right)=f_{c}^{\prime}\left(c^{\theta=1}\right)\left(2+\frac{P}{\sqrt{2 \pi \sigma^{2}}}\right)=f_{s}^{\prime}\left(s^{\theta=1}\right)=g^{\prime}\left(e_{2}^{\theta=1}\right)
$$

where $e_{1}^{\theta=1}=1-c^{\theta=1}-s^{\theta=1}-e_{2}^{\theta=1}=e_{2}^{\theta=1}$.

Claim ii of Proposition 3: $s^{\theta=1}>0$ : this follows from the Inada condition $f_{s}^{\prime}(s) \rightarrow \infty$ as $s \rightarrow 0$. Because $s^{O}=0$, we thus have that $s^{\theta=1}>s^{O}$.

Claim i of Proposition 3: $e^{\theta=1}<e^{O}$. By (6), the outsider's optimal allocation satisfies

$$
g^{\prime}\left(e^{O}\right)=\frac{P}{\sqrt{2 \pi \sigma^{2}}} f_{c}^{\prime}\left(c^{O}\right)
$$

We first compare this to the allocation $\left(\widehat{e}_{1}, \widehat{c}, \widehat{e}_{2}\right)$ satisfying the following condition:

$$
g^{\prime}\left(\widehat{e}_{1}\right)=f_{c}^{\prime}(\widehat{c}) \frac{P}{\sqrt{2 \pi \sigma^{2}}}=g^{\prime}\left(\widehat{e}_{2}\right)
$$

We clearly have that $\widehat{e}_{1}+\widehat{e}_{2}>e^{O}$. We now compare this allocation to another allocation, $\left(\widehat{\widehat{e}}_{1}, \widehat{\widehat{c}}, \widehat{\widehat{e}}_{2}\right)$, which satisfies the following condition:

$$
g^{\prime}\left(\widehat{\widehat{e}}_{1}\right)=f_{c}^{\prime}(\widehat{\widehat{c}})\left(2+\frac{P}{\sqrt{2 \pi \sigma^{2}}}\right)=g^{\prime}\left(\widehat{\widehat{e}}_{2}\right)
$$

Because $\widehat{\widehat{c}}>\widehat{c}$, we cannot determine whether $\widehat{\widehat{e}}_{1}+\widehat{\widehat{e}}_{2}>e^{O}$ or $\widehat{\widehat{e}}_{1}+\widehat{\widehat{e}}_{2}<e^{O}$. We now compare the allocation satisfying (28) with the optimal allocation of the captured party secretary in (25). Using $f_{c}^{\prime}(\cdot)=k_{c} g^{\prime}(\cdot)$ and $f_{s}^{\prime}(\cdot)=k_{s} g^{\prime}(\cdot)$, we can re-write $(25)$ as

$$
g^{\prime}\left(e_{1}^{\theta=1}\right)=k_{c} g^{\prime}\left(c^{\theta=1}\right)\left(2+\frac{P}{\sqrt{2 \pi \sigma^{2}}}\right)=k_{s} g^{\prime}\left(s^{\theta=1}\right)=g^{\prime}\left(e_{2}^{\theta=1}\right)
$$

Clearly, $\widehat{\widehat{e}}_{1}>e_{1}^{\theta=1}$, and $\widehat{\widehat{e}}_{2}>e_{2}^{\theta=1}$. Hence, if $\widehat{\widehat{e}}_{1}+\widehat{\widehat{e}}_{2}<e^{O}$, we must have that $e_{1}^{\theta=1}+e_{2}^{\theta=1}<e^{O}$, regardless of the value of $k_{s}$. If, instead, $\widehat{\widehat{e}}_{1}+\widehat{\widehat{e}}_{2}>e^{O}$, we cannot determine, in general, whether $e_{1}^{\theta=1}+e_{2}^{\theta=1}<e^{O}$ or $e_{1}^{\theta=1}+e_{2}^{\theta=1}>e^{O}$. However, the facts that $\frac{\partial e_{1}^{\theta=1}}{\partial k_{s}}<0$ and $\frac{\partial e_{2}^{\theta=1}}{\partial k_{s}}<0$ imply that, if $k_{s}$ is large enough, then $e_{1}^{\theta=1}+e_{2}^{\theta=1}<e^{O}$.

Claim iii of Proposition 3: We have established that $e_{1}^{\theta=1}+e_{2}^{\theta=1}<e^{O}$ if $k_{s}$ is large enough. Thus, $c^{\theta=1}+s^{\theta=1}>c^{O}$. However, this may be consistent with either $c^{\theta=1}>c^{O}$, or 
with $c^{\theta=1}<c^{O}$.

Finally, because short-term investment may decrease/increase (which decreases/increases $y_{1}^{c}$ and $y_{2}^{c}$ ), economic growth could decrease or increase in the first period. In the second period, growth increases because long-term investment increases (which increases $y_{2}^{s}$ ). If short-term investment is lower than under an outsider party secretary, any reallocation from short-term investment to long-term investment made by the captured party secretary will lead to more long-term growth than the allocation under the outsider party secretary (otherwise, the captured party secretary would not make this reallocation). Hence, growth unambiguously increases in the long run. 